\title{
Effects of Task-Oriented Circuit Class Training on Physical Fitness of Stroke Survivors
}

\author{
Emmanuel Frimpong, Charles Antwi-Boasiako, Edward Ababio, John \\ Ahenkorah and Olajide A. Olawale
}

\begin{abstract}
Aim: The purpose of this study was to assess the effectiveness of task-oriented circuit class training on physical fitness of stroke survivors in the early stages of stroke rehabilitation. Method: This study involved twenty (20) hemiparetic stroke survivors with ten (10) participants each in the task-oriented circuit class training group (TCCTG) and the non-circuit class training group (NCCTG). Participants in TCCTG underwent supervised TCCT with duration of 80 minutes per session, three times per week for 8 weeks in addition to conventional physiotherapy. Assessments were done at baseline and week 8 using resting heart rate (RHR), 5-minute heart rate recovery (5-min HRR), blood pressure (BP), 6-minute walk test (6-MWT), 10-metre walk test (10-MWT) and functional ambulatory category (FAC) score as outcome measures. Results: There were significant reductions in RHR, 5-min HRR, SBP and DBP $(\mathrm{p}<0.05)$ with significant increases in 6-MWT, 10-MWT and FAC score $(\mathrm{p}<0.05)$ within the TCCTG. However, only the 6-MWT and 10-MWT showed significant differences $(\mathrm{p}=0.0432$ and $\mathrm{p}=0.0121)$ in the NCCTG. The means of RHR, 5-min HRR, SBP and DBP were significantly lower in the TCCTG than the NCCTG $(\mathrm{p}<0.05)$. Also, at week 8 , there were significant increases in 6-MWT, 10-MWT and FAC score $(\mathrm{p}<0.05)$ in the TCCTG compared to the NCCTG. Conclusion: Task-oriented circuit class training can improve both physical fitness and functional capacity in stroke survivors in the early stages of stroke rehabilitation.
\end{abstract}

Emmanuel, Frimpong,Assistant Lecturer

Department of Physiology, School of Biomedical and Allied health Sciences, College of Health Sciences, University of Ghana, Ghana

E-mail:frimemma@gmail.com/efrimpong@chs.ug.edu.gh.

Charles, Ant wi-Boasiako,Senior Lecturer

Department of Physiology, School of Biomedical and Allied health Sciences, College of Health Sciences, University of Ghana, Ghana; E-mail: antwiboasiako@chs.edu.gh.

Edward, Ababio, Senior Physiotherapist

Department of Physiotherapy, Korle-Bu Teaching Hospital, Accra, Ghana

E-mail:edwardababio@yahoo.com

John, Ahenkorah, Lecturer

Department of Anatomy, School of Biomedical and Allied health Sciences, College of Health Sciences, University of Ghana, Ghana; E-mail:jahenkorah@ug.edu.gh; daajohnny@yahoo.com

Olajide, A., Olawale, Associate Professor

Department of Physiotherapy, College of Medicine, University

of Lagos, Nigeria

Email:jideolawale@yahoo.com
Key Words: Task-oriented, Circuit Class Training, Physical Fitness, Stroke Survivors

DOI: 10.18376/jesp/2016/v12/i2/111259 


\section{Journal of Exercise Science \& Physiotherapy, Vol. 12, No. 2, 2016 ISSN: 0973-2020 (Print) \\ ISSN: 2454-6089 (Online)}

\section{Introduction}

Stroke is one of the major and leading causes of impairment, disability and handicap in adults (Dean et al., 2000; Bonita et al., 2004; Dobkin, 2005). Following stroke, motor deficits in the upper and lower extremities of the affected body side are the major noticeable impairments with associated limitations and alterations in functional mobility and task performance (Brazzelli et al., 2011; Danielsson et al., 2012). The primary neurological impairments consequently cause deconditioning and predisposition to a sedentary behavior and physical in activity which adversely impact performance of activities of daily living (ADL), increased risk of falls, recurrent stroke and cardiovascular diseases as well as reduced cardiovascular reserves (Da Cunha et al., 2001; Billinger et al., 2014). Low levels of physical fitness have been reported in stroke survivors (Ivey et al., 2005; Saunders et al., 2013; Billinger et al., 2014). Research reports have demonstrated that cardio vascular fitness levels following stroke are only half of age-matched healthy counterparts (Ivey et al., 2005; Patterson et al., 2007). Moreover, the energy cost of ambulation is about twice the normative values of healthy controls (Bellinger et al., 2014). In addition to high energy cost of ambulation, declines in muscle strength and power (Saunders et al., 2008; Gerrits et al., 2009;Brazzelli et al., 2011) as well as post-stroke fatigue (Duncan et al., 2012) further encourage sedentary lifestyle, physical inactivity and decreased physical fitness. Generally, fitness training in stroke survivors has received little attention, particularly soon after stroke (Saunders et al., 2009).Although physical fitness decline with the associated post-stroke disabilities has been well highlighted in literature, most stroke rehabilitations do not emphasize fitness training (Saunders et al., 2009; Smith et al., 2012). However, improving fitness in stroke survivors can reduce fatigue, fall rates and fractures, energy cost of ambulation and functional limitations as well as improved functional independence and quality of life (Saunders et al., 2013).Studies have employed either land-based and water-based exercises of different techniques to improve cardiovascular fitness (Macko et al., 2001; da Cunha et al., 2002; Katz-Leurer et al., 2003; Aidar et al., 2007; Lennon et al., 2008; Toledano-Zarhi et al., 2011), muscular strength (Bale and Strand, 2008; Sims et al., 2009), or both cardiovascular fitness and strength (Mead et al., 2007; Donaldson et al., 2009; Cooke et al., 2010). Outcome measures such as blood pressure (BP), resting heart rate (RHR) and heart rate recovery (HRR) (Da Cunha et al., 2002; Lennon et al., 2008; Toledano-Zarhi et al., 2011) have been used to evaluate cardiovascular fitness. The six (6)-minute walk test (6-MWT) and ten-metre walk test (10-MWT) have been employed to assess the efficacies of walking capacity and walking speed respectively in mobility studies (Olawale et al., 2011; Globas et al., 2012; Kang et al., 2012; van de Port et al., 2012; Ada et al., 2013). Also, functional ambulatory category (FAC) score has been used to assess functional capacity(Da Cunha et al., 2002; Pohl et al., 2002; Mead et al., 2007).Despite these advances in rehabilitation, emerging evidence suggests that therapy after stroke should focus on practice of functional tasks (van Peppen 2004; English and Hillier, 2010; Teasell and Hussein, 2014). Task-specific training principle is practised in mobility training and has been shown to improve ambulatory capacity (Ada et al., 2010; Duncan et al., 2011; Langhammer and Stanghelle; 2011; Teasell and Hussein, 2014). Task-specific training can be performed over-ground or organised into circuit format(Carr and Shepherd, 1998; Teasell and Hussein, 2014).Task-oriented circuit class training (TCCT) is a type of task-specific training that utilises active exercises and 


\section{Journal of Exercise Science \& Physiotherapy, Vol. 12, No. 2, 2016 ISSN: 0973-2020 (Print) \\ ISSN: 2454-6089 (Online)}

activities that are functionally task-specific (English and Hillier, 2010). In this model of training, participants complete a series of workstations arranged in a circuit within a group setting (English et al., 2007; Wevers et al., 2009). Although many of the activities and exercises may be fitness-biased, the primary goal is to achieve repetitive practice of task-specific training of everyday motor tasks (English and Hillier, 2010).The TCCT has been investigated in many studies especially, to evaluate its effects on mobility or ambulatory functions in stroke survivors compared with conventional therapy (Salbach et al., 2004; Mudge et al., 2009; English and Hillier, 2010; Van de Port et al., 2012; Frimpong et al., 2014). However, whether or not TCCT would improve physical fitness of stroke survivors is unclear (English and Hillier, 2010) and has not been well studied. It is not known whether TCCT can improve physical fitness and functional capacity in the early stages of rehabilitation after stroke. Therefore, the primary aim of this study was to investigate the effectiveness of task-oriented circuit class training on physical fitness of stroke survivors in early stroke rehabilitation. The secondary aim was to evaluate the effects of task-oriented circuit training on functional capacity of stroke survivors. We hypothesised that task-oriented circuit class training would improve physical fitness and functional capacity in the early phase of stroke rehabilitation.

\section{Materials and Methods}

\section{Study Site and Participants}

The study was conducted at the Physiotherapy Department of Korle Bu Teaching Hospital, Accra, Ghana. This hospital is the largest referral hospital in Ghana with over 1600-bed capacity. The study recruited twenty (20) new hemiparetic stroke survivors referred for physiotherapy. To participate in the study, patients had to meet the following inclusion criteria: (1) first or second stroke resulting in right or left sided hemiparesis, (2) muscle power of at least grade threeand (3) functional ambulatory category (FAC) score of at least three. Patients were excluded from the study if they had (1) bilateral hemiparesis (2) FAC score of less than grade three(3) muscle power of less than grade three, (4) fracture in the lower limbs, (5) aphasia, (6) cardiac arrhythmias and any such conditions for which exercises are contraindicated (Frimpong et al., 2014). The Ethical and Protocol Review Committee (EPRC) of University of Ghana School of Allied Health Sciences approved the study. All participants gave written informed consent after having understood explanations of the study protocol and any potential risk that could be encountered.

\section{Procedure}

The study participants were randomized into two groups: the task-oriented circuit class training group (TCCTG) and non-circuit class training group (NCCTG) or control group. Randomization was done using 20 cards bearing the names of the groups and participants' numbers. Thus, ten (10) participants were recruited into each group. Both groups received treatments three times per week for eight (8) weeks.

The Task-Oriented Circuit Class Training Group (TCCTG)

The TCCT intervention began with familiarization sessions for participants to acquaint themselves with the workstations in the circuit. Participants were introduced to and tested on all the workstations in the circuit to estimate the level of capacities of each participant in terms of sets, repetitions and times for the tasks and what they were supposed to do during the training (Frimpong et al., 2014). 


\section{Journal of Exercise Science \& Physiotherapy, Vol. 12, No. 2, 2016 ISSN: 0973-2020 (Print) \\ ISSN: 2454-6089 (Online)}

The intervention for the TCCTG involved warm-ups, circuit class training and cooldowns. The warm-up ( 5 minutes) involved passive and active range of motions of major joints of the body. The cool-down sessions ( 5 minutes) involved passive stretching of lower limbs and controlled breathing exercises. The circuit comprised ten (10) workstations namely: over-ground walking, sit-to-stand, treadmill walking, push-ups, squatting, straight leg raise (SLR), stairs walking (stairs ascents and descents), cycling, backward walking and bridging exercises. The tasks at each workstation were performed for 5 minutes. At least 20 repetitions of sit-to-stand, push-ups, squatting, straight leg raise and bridging within 5 minutes were encouraged from the beginning of the training. A 2minute rest period was allowed between workstations. Therefore, the TCCT lasted for 80 minutes per session. The TCCT was performed three times per week for eight weeks. The intensity of the TCCT was targeted between 10 (light) and 15 (hard or heavy) of the Borg's scale of rating of perceived exertion (RPE) (Borg, 1982). Participants progressed through the study period by adjusting the duration, sets and repetitions of the workstations in the circuit. Thus, participants performed the TCCT at light intensity at the beginning and hard intensity towards the end of the study. The speed of the treadmill was between 0.9- 3.0kilometres per hour $(\mathrm{km} / \mathrm{hr})$. Participants were encouraged to train as hard as possible and were given verbal feedbacks for tasks improvements (Dean et al., 2000). The same circuit was used throughout the study period; though parameters were varied based on progress of participants and the order of performing tasks at the various workstations was varied throughout the study period. In addition, the TCCTG received the usual conventional physiotherapy as the NCCTG.

The Non-Circuit Class Training Group (NCCTG)

The NCCTG constituted the control group for the study. Participants in the group only received the usual conventional therapy of passive and active exercises. Participants performed upper limb strengthening exercises, walking re-education, as well as standing and balance retraining carried out between parallel bars. Participants performed walking re-education by starting in parallel bars and progressed to free over-ground walking with or without walking aids.

Assessments on Outcome Measures

Both the TCCTG and NCCTG were evaluated at baseline and at the end of the training (week 8).The outcome measures used were anthropometric parameters, heart rate recovery (HRR), blood pressure (BP), 6-minute walk test (6-MWT), 10-metre walk test (10-MWT) test and functional ambulatory category scores (FACS).

\section{Anthropometric Parameters}

Height (HT)was measured to the nearest metre with the participants shoeless using a stadiometer (Seca, model 202, Germany). Weight (WT)was measured to the nearest kilogram using a scale (Mettler, Model TE120 ME36400, Switzerland) with participants' shoeless and wearing light clothing. Body mass index (BMI) was calculated from the height and the weight (weight/square of height) for each participant.

Resting Heart Rate (RHR) and Heart rate recovery (HRR)

Resting heart rates (RHR) were measured at rest with an electronic monitor (Omron, UK) before the 6-minute walk test. Heart rates were also measured five (5) minutes after cessation of the walk test. This was done to assess whether heart rates of the participants would recover five minutes after the walk test to their resting heart rates.

Blood Pressure (BP) 


\section{Journal of Exercise Science \& Physiotherapy, Vol. 12, No. 2, 2016 ISSN: 0973-2020 (Print) \\ ISSN: 2454-6089 (Online)}

Blood pressure of participants was measured at baseline and at the end of the 8-week training. Following 10 minutes of resting in seated position, blood pressure was measured using an aneroid sphygmomanometer at the brachial artery with the arm supported at the level of the heart. The blood pressure was recorded as a ratio of systolic blood pressure (SBP) $\mathrm{mmHg}$ to diastolic blood pressure (DBP) $\mathrm{mmHg}$.

The 6-Minute Walk Test (6-MWT)

The 6-minute walk test was the test done to assess the muscular endurances and walking capacity of participants. Participants walked over a 40-metre walkway of the remedial therapeutic gymnasium for 6 minutes. The total distance covered during the 6 minutes was then calculated in metres. Prior to the test, subjects were told that they could rest but that was allowed only at their request and it could be either sitting or standing and they were again told they could walk with or without their walking aids (Lord and Rochester, 2005).

The 10-Metre Walk Test (10-MWT)

This test was done to assess the walking speed of participants over a ten-metre walkway. A 14-meter walkway was marked on the floor of the gymnasium. This was done to eliminate acceleration and deceleration during the test. Participants were told before the test that they could walk with or without walking aid and they were required to walk at their self-selected walking speeds (Dean, et al., 2000). A stop clock was used to record the time taken by the subjects to cover the ten-metre distance over the 14-metre walk way. The stop clock was started simultaneously with the initiation of movements by the participants. The time used over the 10-metre walkway was then recorded in seconds. Three recordings were made and the average time calculated.

The Functional Ambulatory Category (FAC)Scores

The functional ambulatory category scores were assessed while participants were walking to evaluate the level of dependency of participants in performing functional activities. FAC is a six-point hierarchical rating scale that reflects the assistance a person requires to walk. This scale allows easy classification of patients in respect of their walking ability, with maximum score signifying ability to ambulate independently on non-level surfaces (Holden et al., 1984).

The data were analysed using the Statistical Package for Social Sciences (SPSS) version20. All data were presented as mean plus or minus standard deviation (mean $\pm \mathrm{SD}$ ). Paired and unpaired $t$ - tests were used to find significant differences in the means of the outcome measures: HT, WT, BMI, RHR, HRR, DBP, SBP, 6-mWT, 10-MWTand FAC scores within and between the groups respectively. A p-value of less than $0.05(\mathrm{p}<0.05)$ was considered significant.

\section{Results}

The study involved twenty (20) participants comprising twelve (12) males and eight (8) females. The mean age of participants was $(60.1 \pm 3.5)$ years. The mean time since stroke was $(5.4 \pm 1.1)$ weeks. Fourteen (14) and six (6) of the participants had ischaemic and haemorrhagic strokes respectively. Thirteen (13) and seven (7) of the participants presented with left and right hemiparesis respectively. Table 1 shows the demographic and anthropometric parameters of the study participants.

Unpaired $t$-test analysis showed that the mean differences in age, height, weight and BMI between the TCCTG and NCCTG were not significant ( $p>0.05)$. 
Table 1. Characteristics of study participants

\begin{tabular}{llll}
\hline Anthropometric Variables & $\begin{array}{l}\text { TCCTG }(\mathbf{n = 1 0}) \\
(\text { Mean } \pm \text { SD) }\end{array}$ & $\begin{array}{l}\text { NCCTG }(\mathbf{n = 1 0}) \\
(\text { Mean } \pm \text { SD) }\end{array}$ & P - value \\
\hline Age $(\mathrm{yrs})$ & $59.1 \pm 4.0$ & $61.0 \pm 2.7$ & $\mathbf{0 . 2 3 4 7}$ \\
Height $(\mathrm{m})$ & $1.6 \pm 0.1$ & $1.6 \pm 0.2$ & $\mathbf{0 . 3 8 7 1}$ \\
Weight $(\mathrm{kg})$ & $69.2 \pm 6.1$ & $67.8 \pm 7.3$ & $\mathbf{0 . 6 4 7 4}$ \\
BMI $\left(\mathrm{kg} / \mathrm{m}^{2}\right)$ & $28.3 \pm 4.3$ & $26.0 \pm 5.5$ & $\mathbf{0 . 3 2 1 6}$ \\
\hline
\end{tabular}

TCCTG - task-oriented circuit class training group; NCCTG - non-circuit class training group; $\mathrm{SD}$ - standard deviation; BMI - body mass index; yrs - years; $\mathrm{m}$ - metres; $\mathrm{kg}$ - kilogram; $\mathrm{kg} / \mathrm{m}^{2}-$ kilogram per meters square; $\mathrm{n}$ - sample size.

Table 2. Treatment effects on Outcome Measures at baseline and week 8 within the TCCTG $(\mathbf{n}=10)$

\begin{tabular}{|c|c|c|c|}
\hline $\begin{array}{l}\text { Outcome } \\
\text { Measures }\end{array}$ & $\begin{array}{l}\text { Baseline } \\
(\text { Mean } \pm \text { SD })\end{array}$ & $\begin{array}{l}8 \text { weeks } \\
(\text { Mean } \pm \text { SD) }\end{array}$ & P-value \\
\hline $\begin{array}{l}\text { RHR (bpm) } \\
5 \text { Min HRR (bpm) }\end{array}$ & ${ }^{\#} 80.3 \pm 3.0$ & $73.5 \pm 3.1$ & $\begin{array}{l}0.0004 * \\
<0.0001 *\end{array}$ \\
\hline $\mathrm{SBP}(\mathrm{mmHg})$ & ${ }^{\#} 92.1 \pm 4.3$ & $76.1 \pm 2.9$ & $0.0103 *$ \\
\hline DBP (mmHg) & $131.3 \pm 6.0$ & $125.3 \pm 3.5$ & $0.0004 *$ \\
\hline 6-MWT (m) & $\begin{array}{l}90.0 \pm 2.9 \\
278.7 \pm 20.4\end{array}$ & $\begin{array}{l}84.9 \pm 2.0 \\
360.2 \pm 26.0\end{array}$ & $<0.0001 *$ \\
\hline 10-MWT (s) & $40.2 \pm 2.9$ & $19.5 \pm 1.5$ & $<0.001 *$ \\
\hline FAC Score & $3.8 \pm 0.5$ & $4.6 \pm 0.5$ & 0.011* \\
\hline
\end{tabular}

RHR- resting heart rate; bpm - beats per minute; HRR - heart rate recovery; 5 Min HRR - heart rate recovery in 5 minutes; SBP - systolic blood pressure; DBP - diastolic blood pressure; mmHg - millimetres of mercury; 6-MWT - Six-Minute Walk test, 10MWT - Ten-Minute Walk Test, FAC - Functional Ambulatory Category; $\mathrm{n}$ - sample size.

*Indicates mean differences in RHR, 5 min HRR, SBP, DBP, 6-MWT, 10-MWT and FAC within the CTG between baseline and week 8 were significant $(\mathrm{p}<0.05)$.

\#Indicates mean difference between RHR and 5 min HRR was significant ( $\mathrm{p}=0.0001)$ at baseline within the TCCTG.

Table 3. Treatment effects on Outcome Measures at baseline and week 8 within the NCCTG $(n=10)$

\begin{tabular}{lccc}
\hline $\begin{array}{l}\text { Outcome } \\
\text { Measures }\end{array}$ & $\begin{array}{l}\text { Baseline } \\
(\text { Mean } \pm \text { SD) }\end{array}$ & $\begin{array}{l}\text { 8 weeks } \\
(\text { Mean } \pm \text { SD) }\end{array}$ & P-value \\
\hline RHR $(b p m)$ & ${ }^{\#} 78.7 \pm 1.8$ & ${ }^{\S} 79.7 \pm 1.2$ & $\mathbf{0 . 1 5 8 2}$ \\
5 Min HRR $(b p m)$ & & & $\mathbf{0 . 0 6 3 4}$ \\
SBP $(\mathrm{mmHg})$ & ${ }^{*} 91.2 \pm 4.9$ & ${ }^{\S} 88.3 \pm 1.6$ & $\mathbf{0 . 1 8 5 2}$ \\
DBP $(\mathrm{mmHg})$ & $131.1 \pm 5.2$ & $130.0 \pm 3.6$ & $\mathbf{0 . 0 6 5 6}$ \\
$6-\mathrm{MWT}(\mathrm{m})$ & $89.8 \pm 3.2$ & $88.4 \pm 1.9$ & $\mathbf{0 . 0 4 3 2} *$ \\
& $251.6 \pm 18.9$ & $262.3 \pm 17.9$ & \\
\hline
\end{tabular}




\begin{tabular}{llll}
\hline 10-MWT (s) & $46.3 \pm 2.7$ & $34.5 \pm 3.1$ & $\mathbf{0 . 0 1 2 1 *}$ \\
FAC Score & $3.3 \pm 0.5$ & $3.4 \pm 0.5$ & $\mathbf{0 . 5 9 1 1}$ \\
\hline
\end{tabular}

RHR- resting heart rate; bpm - beats per minute; HRR - heart rate recovery; 5 Min HRR - heart rate recovery in 5 minutes; SBP - systolic blood pressure; DBP - diastolic blood pressure; $\mathrm{mmHg}$ - millimetres of mercury; 6-MWT - Six-Minute Walk test, 10-MWT - Ten-Minute Walk Test, FAC - Functional Ambulatory Category; $\mathrm{n}$ - sample size.

*Indicates mean differences in 6-MWT and 10-MWT within the NCTG between baseline and week 8 were significant $(\mathrm{P}<0.05)$. \#Indicates mean difference between RHR and 5 min HRR at baseline was significant $(\mathrm{p}<0.0001)$ within the NCCTG. $\$$ Indicates mean difference between RHR and 5 min HRR at week 8 was significant $(\mathrm{p}<0.0001)$ within the NCCTG.

Table 4. Comparing Treatment effects on Outcome Measures at baseline between the TCCTG and NCCTG $(n=20)$

\begin{tabular}{llll}
\hline $\begin{array}{l}\text { Outcome } \\
\text { Measures }\end{array}$ & $\begin{array}{l}\text { TCCTG } \\
(\text { Mean } \pm \text { SD) }\end{array}$ & $\begin{array}{l}\text { NCCTG } \\
\text { (Mean } \pm \text { SD) }\end{array}$ & P-value \\
\hline RHR (bpm) & $80.3 \pm 3.0$ & $78.7 \pm 1.8$ & $\mathbf{0 . 1 6 1 7}$ \\
5 Min HRR (bpm) & & & $\mathbf{0 . 6 6 6 8}$ \\
SBP $(\mathrm{mmHg})$ & $92.1 \pm 4.3$ & $91.2 \pm 4.9$ & $\mathbf{0 . 9 3 7 4}$ \\
DBP $(\mathrm{mmHg})$ & $131.3 \pm 6.0$ & $131.1 \pm 5.2$ & $\mathbf{0 . 7 7 0 7}$ \\
6-MWT (m) & $90.0 \pm 2.9$ & $89.8 \pm 3.2$ & $\mathbf{0 . 0 3 4 1} *$ \\
& $278.7 \pm 20.4$ & $251.6 \pm 18.9$ & \\
10-MWT (s) & $40.2 \pm 2.9$ & $46.3 \pm 2.7$ & $\mathbf{0 . 0 5 1 2}$ \\
FAC Score & $3.8 \pm 0.5$ & $3.3 \pm 0.5$ & $\mathbf{0 . 0 6 5 1}$ \\
\hline
\end{tabular}

RHR- Resting Heart Rate; Bpm - Beats Per Minute; HRR - Heart Rate Recovery; 5 Min HRR - Heart Rate Recovery In 5 Minutes; SBP - Systolic Blood Pressure; DBP - Diastolic Blood Pressure; Mmhg - Millimetres Of Mercury; 6-MWT - Six-

Minute Walk Test, 10-MWT - Ten-Minute Walk Test, FAC - Functional Ambulatory Category; N - Sample Size. *Indicates Mean Difference In 6-Mwtbetween TCCTG And NCCTG At Baseline Was Significant $(\mathrm{P}<0.05)$.

There were no significant differences in mean RHR, 5 min HRR, SBP, DBP, 10-MWT and FACS at baseline between TCCTG and NCCTG ( $>>0.05)$.

Table 5. Comparing Treatment effects on Outcome Measures at week 8between the TCCTG and NCCTG $(n=20)$

\begin{tabular}{|c|c|c|c|}
\hline $\begin{array}{l}\text { Outcome } \\
\text { Measures }\end{array}$ & $\begin{array}{l}\text { TCCTG } \\
(\text { Mean } \pm \text { SD })\end{array}$ & $\begin{array}{l}\text { NCCTG } \\
(\text { Mean } \pm \text { SD })\end{array}$ & P-value \\
\hline RHR (bpm) & $73.5 \pm 3.1$ & $79.7 \pm 1.2$ & $0.0002 *$ \\
\hline 5 Min HRR (bpm) & & & $<0.0001 *$ \\
\hline $\mathrm{SBP}(\mathrm{mmHg})$ & $76.1 \pm 2.9$ & $88.3 \pm 1.6$ & $0.0058 *$ \\
\hline $\mathrm{DBP}(\mathrm{mmHg})$ & $125.3 \pm 3.5$ & $130.0 \pm 3.6$ & $0.0005 *$ \\
\hline \multirow[t]{2}{*}{ 6-MWT (m) } & $84.9 \pm 2.0$ & $88.4 \pm 1.9$ & 0.0130* \\
\hline & $360.2 \pm 26.0$ & $262.3 \pm 17.9$ & \\
\hline 10-MWT (s) & $19.5 \pm 1.5$ & $34.5 \pm 3.1$ & $0.0285^{*}$ \\
\hline FAC Score & $4.6 \pm 0.5$ & $3.4 \pm 0.5$ & $0.0367 *$ \\
\hline
\end{tabular}

RHR- resting heart rate; bpm - beats per minute; HRR - heart rate recovery; 5 Min HRR - heart rate recovery in 5 minutes; $\mathrm{SBP}$ - systolic blood pressure; DBP - diastolic blood pressure; mmHg - millimetres of mercury; 6-MWT - Six-Minute Walk test, 10-MWT - Ten-Minute Walk Test, FAC - Functional Ambulatory Category; n - sample size.

*Indicates mean differences in RHR, 5 min HRR, SBP, DBP, 6-MWT, 10-MWT and FAC were significant (p<0.05) between the TCCTG and NCCTG at week 8 . 


\section{Journal of Exercise Science \& Physiotherapy, Vol. 12, No. 2, 2016 ISSN: 0973-2020 (Print) \\ ISSN: 2454-6089 (Online)}

\section{Discussion}

This study explored the effectiveness of task-oriented circuit class training on improving physical fitness of stroke survivors. The major finding of this study was that, taskoriented circuit class training improved physical fitness of stroke survivors in the early stages of rehabilitation after stroke. The outcome measures assessed significantly improved at the end of the training period in the task-oriented circuit class training group as compared to the control group.

Cardiovascular fitness was assessed with resting heart rate (RHR), heart rate recovery after five (5) minutes (5 min HRR) and blood pressure (SBP and DBP). At the end of the training, the RHR, 5 min HRR, SBP and DBP significantly reduced in the TCCTG as compared to the NCCTG. These findings concur with other studies of stroke populations (Potempa et al., 1995; Macko et al., 2001; Da Cunha et al., 2002; Katz-Leurer et al., 2003; Lennon et al., 2008; Toledano-Zarhi et al., 2011). Thus, cardiovascular fitness improved significantly after the circuit class training with lower RHR, faster recovery of HR to pre-6-MWT and lower blood pressure. However, cardiovascular fitness did not improve in the NCCTG. Brazzelli et al. (2011) reported that physical fitness training may reduce blood pressure, improve vascular risk factors as well as reduce mortality in coronary heart disease. Cornelissen et al. (2013) demonstrated that endurance exercise beneficially affects ambulatory blood pressure. The cardiovascular fitness being the cornerstone of physical fitness may have improved due to improved fitness reserve or aerobic capacity and exercise tolerance (Saunders et al., 2013) gained during the training. Therefore, improved physical fitness levels may be beneficial in reducing fatigue, fall rates and fractures, high energy cost of ambulation as well as improving independence, mood and quality of life (Kluding et al., 2011).

The task-oriented circuit class training significantly improved walking capacity as measured by the 6-MWT. This finding supports reports of other studies utilising taskoriented circuit interventions for improving mobility after stroke (Dean et al., 2000; Salbach et al., 2004; Blennerhassett and Dite, 2004; Pang et al., 2005; Mudge et al., 2009; Wevers et al., 2009; van de Port et al., 2012).The improvement in walking capacity may stem from increased cardiovascular fitness at the end of the training. Studies have shown that walking improvements in stroke survivors after task-oriented cardiovascular training may occur due to an increased fitness reserve as well as facilitation of motor learning and improved gait performance (Saunders et al., 2009). Also, improvement in walking capacity may have resulted from the lower limb-biased workstations incorporated into the study which effectively improved strength and endurance. Dean et al. (2000) reported that task-related circuit class focused on improving strength and endurance of affected lower limbs effectively improved locomotor function in chronic stroke. English and Hillier (2010) observed that studies that recorded significant improvements in 6-MWT emphasised on continuous and consistent walking practices. Further, fitness training reduces disability mediated by improved mobility and balance after stroke (Saunders et al., 2013). Functionally, the improvement in the 6-MWT is relevant since it has been found to be a stronger predictor of community ambulatory capacity (Mudge et al., 2009). Hence, the improved walking capacity may suggest increased ability to perform prolonged activities.

The walking speed (as measured by 10-MWT) significantly increased in the TCCTG as compared to the NCCTG. This result is in agreement with findings of studies that investigated the efficacy of task-oriented circuit class training on walking or gait speed 


\section{Journal of Exercise Science \& Physiotherapy, Vol. 12, No. 2, 2016 ISSN: 0973-2020 (Print) \\ ISSN: 2454-6089 (Online)}

(Dean et al., 2000; Salbach et al., 2004; Mudge et al., 2009; Wevers et al., 2009; van de Port et al., 2012). The increase in walking speed by the task-oriented circuit training may be due to the improved cardiovascular fitness and walking capacity. Moreover, the design of the circuit favoured walking speed. As an important skill- or performance-related component of physical fitness, walking speed has been demonstrated to be a valid and responsive measure of improvement in walking ability in individuals after stroke (Salbach et al., 2001; Kollen et al., 2006). However, Pohl et al. (2002) asserted that walking speed must be specifically and aggressively trained in stroke survivors before it increases.

In this study, in addition to the 6-MWT, functional capacity was also assessed using the factional ambulatory category (FAC) score. The FAC score significantly improved in the TCCTG as compared with the NCCTG. Similar results were obtained from other taskoriented training interventions (da Cunha et al., 2002; Pohl et al., 2002; Mead et al., 2007). The FAC score gives an indication of the level of dependency a patient requires for ambulation (Saunders et al., 2009). The observed improvement in functional capacity may be due to a better motor function (Wevers et al., 2009; Rensink et al., 2009; Saunders et al., 2013). Moreover, improvements in cardiovascular fitness, walking capacity and walking speed are expected to translate into functional ambulatory independence. Furthermore, task-oriented based exercises are shown to be most effective in attaining optimal motor function and independence in daily activities in acute stroke rehabilitation (Rensink et al., 2009; Wevers et al., 2009). Thus, the task-oriented circuit training group showed significant improvement in functional capacity. Improving functional capacity in stroke survivors can reduce the physiologic burden of performing activity of daily living and instrumental activity of daily living (IADL), thereby increasing volume of daily physical activity accumulation (Kelly et al, 2003).

Engagement in task-oriented trainings has been speculated to be associated with improved fitness, mobility and physical function (Saunders et al., 2013).In agreement with other stroke rehabilitation studies employing task-oriented training, this study shows that improvements in fitness levels and functional capacity of participants were due to the task-related practices of the circuit training (Dean et al., 2000; Yocheved et al., 2001; Salbach et al., 2004; English and Hillier, 2010; Van de Port et al., 2012; Saunders et al., 2013). Given that, both study groups (TCCTG and NCCTG) received the same conventional therapy, the observed improvement in physical fitness of patients in the TCCTG was mainly due to the task-oriented circuit class training. The findings of this study further confirm that task-oriented circuit class training is safe and feasible soon after stroke (Blennerhassett and Dite, 2004) and could be used to concurrently improve physical fitness and physical functional performances. Thus, improving fitness in stroke survivors can reduce stroke-related disability if training is task-oriented. The observed positive effects of the task-oriented circuit training on physical fitness used in this study could be explained on the basis of components of the circuits, that is, the effects were specific to the training (Dean et al., 2000; English and Hillier, 2010). Thus, benefits reflect the principle of the specificity of training response (Saunders et al., 2013). It has been established that benefits observed in trainings for fitness, mobility and physical function are task-oriented (Saunders et al., 2013).

\section{Conclusion}

The present study demonstrates that task-oriented circuit class training can improve both physical fitness and functional capacity in stroke survivors. Improving fitness in stroke 


\section{Journal of Exercise Science \& Physiotherapy, Vol. 12, No. 2, 2016 ISSN: 0973-2020 (Print) \\ ISSN: 2454-6089 (Online)}

survivors can reduce stroke-related disability if training is task-oriented. The study further encourages the application of task-oriented circuit training in rehabilitation soon after stroke. Further trials of longer study duration with large sample size are required to confirm the effectiveness of task-oriented circuit class training on physical fitness in stroke survivors and the retention of fitness after the training.

\section{Acknowledgements}

The authors express sincere gratitude to the staff of Department of Physiotherapy, KorleBu Teaching Hospital, Accra, Ghana and all the patients who participated in this study. Emmanuel Frimpong conceptualized, designed the study, Collected data and drafted the manuscript, Charles Antwi-Boasiako analysed data, interpreted the analyses, Edward Ababio co-designed the study and data collection, John Ahenkorah co-drafted the manuscript and data interpretation, OA Olawale co-designed the study and critically revised the manuscript for important intellectual content. All authors read and approved the final version of the article.

\section{References}

Ada, L., Dean, C.M.and Lindley, R. 2013. Randomized trial of treadmill training to improve walking in community-dwelling people after stroke: the AMBULATE trial. International Journal of Stroke; 8(6):436-44.

Ada, L., Dean, C.M., Morris, M.E., Simpson, J.M. and Katrak, P. 2010. Randomized Trial of Treadmill Walking With Body Weight Support to Establish Walking in Subacute Stroke. The MOBILISE Trial. Stroke; 41:1237- 1242.

Aidar, F.J., Silva, A.J., Reis, V.M., Carniero, A. and Carniero-Cotta, S. 2007. A study on the quality of life in ischaemic vascular accidents and its relation to physical activity. Revista de Neurología;45:518-22.

Bale, M. and Strand, L.I. 2008. Does functional strength training of the leg in subacute stroke improve physical performance? A pilot randomized controlled trial. Clinical Rehabilitation;22(10-11):911-21.

Billinger, S.A, Taylor, J.M. and Quaney, B.M. 2012. Cardiopulmonary response to exercise testing in people with chronic stroke: a retrospective study. Stroke Res Treat; 2012:987637.

Blennerhassett, J. and Dite, W. 2004. Additional task-related practice improves mobility and upper limb function early after stroke: a randomised controlled trial. Australian Journal of Physiotherapy;50:219-24.

Bonita, R., Mendis, S., Truelsen, T., Bogousslavsky, J., Toole, J. and Yatsu, F. 2004. The global stroke initiative. Lancet Neurol; 3:391-3. doi: 10.1016/S14744422(04)00800-2.

Borg, G.A.V. 1982. Psychophysical bases of perceived exertion. Med Sci Sports Exerc;14:377-381.

Brazzelli, M., Saunders, D.H., Greig, A.C. and Mead, G.E. (2011 ). Physical fitness training for stroke patients. The Cochrane Collaboration. DOI: 10.1002/14651858.CD003316.pub4.

Cooke, E.V., Tallis, R.C., Clark, A., Pomeroy, V.M. 2010. Efficacy of functional strength training on restoration of lower- limb motor function early after stroke: phase I randomized controlled trial. Neurorehabilitation and Neural Repair;24(1):8896.

Cornelissen, V.A., Buys, R. and Smart, NA. 2013. Endurance exercise beneficially affects ambulatory blood pressure: a systematic review and meta-analysis. Journal of Hypertension;31 (4):639-48. 


\section{Journal of Exercise Science \& Physiotherapy, Vol. 12, No. 2, 2016 ISSN: 0973-2020 (Print)

Da Cunha, F.T.I., Lim, P.A.C. and Huma, Q. 2001. A comparison of regular rehabilitation and regular rehabilitation with supported treadmill ambulation training for acute stroke patients. Journal of Rehabilitation Research and Development; 38(2):243-2452.

Danielsson, A., Willen, C. and Sunnerhagen, K.S. 2012. Physical activity, ambulation, and motor impairment late after stroke. Stroke Res Treat;2012:818513.

Dean, C.M., Richards, C.L. and Malouin, F. 2000. Task-related circuit training improves performance of tasks chronic stroke. Arch Phys Med Rehabil;81:409-417.

Dobkin, B.H. 2005. Clinical practice: rehabilitation after stroke. N Engl J Med; 21:16771684.

Donaldson, C., Tallis, R., Miller, S., Sunderland, A., Lemon, R. and Pomeroy, V. 2009. Effects of conventional physical therapy and functional strength training on upper limb motor recovery after stroke: a randomized phase II study. Neurorehabilitation and Neural Repair;23(4):389-97.

Duncan, F., Kutlubaev, M.A., Dennis, M.S., Greig, C. and Mead, G.E. 2012. Fatigue after stroke: a systematic review of associations with impaired physical fitness. Int J Stroke;7:157-162.

Duncan, P.W., Sullivan, K.J., Behrman,A.L., Azenet, S.P., Wu, S.S., Nadeau, S.E., Dobkin, B.H., Dorian,K.R., Tilson, J.K., Cen, S. and Hayden, S.K. 2011. Bodyweight-supported treadmill rehabilitation after stroke. NEJM; 364:2026-36.

English, C., Hillier, S., Stiller, K. and Warden-Flood, A. 2007. Circuit class therapy versus individual physiotherapy sessions during inpatient stroke rehabilitation: a controlled trial. Archives of Physical Medicine and Rehabilitation;88:955-63.

English, C. and Hillier, S.L. 2010. Circuit class therapy for improving mobility after stroke. Cochrane Database of Systematic Reviews (2). DOI: 10.1002/14651858.CD007513.pub2.

Frimpong, E., Olawale, O.A., Antwi, D.A., Antwi-Boasiako, C. and Dzudzor, B. 2014. Task- oriented circuit training improves ambulatory functions in acute stroke: a randomized controlled trial. J. Med. Med. Sci; 5(8):169-175.

Gerrits, K.H., Beltman, M.J., Koppe, P.A., Konijnenbelt, H., Elich, P.D. and de Haan, A. 2009. Isometric muscle function of knee extensors and the relation with functional performance in patients with stroke. Archives of Physical Medicine and Rehabilitation;90(3):480-7.

Goulding, R., Thompson, D. and Beech, C. 2004. Caring for patients with hemiplegia in an arm following stroke. Br $J$ Nur;13(9):534-9. doi: 10.12968/bjon.2004.13.9.12966.

Holden, M.K., Gill, K.M. and Magliozzi, M.R.d 1984. Clinical gait assessment in the neurologically impaired. Reliability and meaningfulness. Phys Ther;64:35-40.

Ivey, F.M., Macko, R.F., Ryan, A.S. and Hafer-Macko, C.E. 2005. Cardiovascular health and fitness after stroke. Top Stroke Rehabil;12(1):1-16.

Kang, H.K., Kim, Y., Chung, Y. and Hwang, S. 2012. Effects of treadmill training with optic flow on balance and gait in individuals following stroke: randomized controlled trials. Clinical Rehabilitation;26(3):246-55.

Katz-Leurer, M., Carmeli, E. and Shochina, M. 2003. The effect of early aerobic training on independence six months post stroke. Clinical Rehabilitation;17(7):735.

Kelly, J.O., Kilbreath, S.L., Davis, G.M., Zeman, B. and Raymond J. 2003. Cardiorespiratory fitness and walking ability in subacute stroke patients. Arch Phys Med Rehabil; 84(12):1780-1785.

Kluding, P.M., Tseng, B.Y. and Billinger, S.A. 2011. Exercise and executive function in individuals with chronic stroke: a pilot study. J Neurol Phys Ther;35(1):11-17.

Kollen, B., Kwakkel, G. and Lindeman, E. 2006. Time dependency of walking classification in stroke. Physical Therapy;86(5):618-25. 


\section{Journal of Exercise Science \& Physiotherapy, Vol. 12, No. 2, 2016 ISSN: 0973-2020 (Print)

Langhammer, B. and Stanghelle, J.K. 2011. Can physiotherapy after stroke based on the Bobath concept result in improved quality of movement compared to the motor relearning programme. Physiother Res Int; 16(2):69-80.

Lennon, O., Carey, A., Gaffney, N., Stephenson, J. and Blake, C. 2008. A pilot randomized controlled trial to evaluate the benefit of the cardiac rehabilitation paradigm for the non-acute ischaemic stroke population. Clinical Rehabilitation; 22(2):125-33.

Lord, S.E.and Rochester, L. 2005. Measurement of community ambulation after stroke: current status and future developments. Stroke; 36(7), pp. 1457-1461.

Macko, R.F., Ivey, F.M., Forrester, L.W., Hanley, D., Sorkin, J.D. and Katzel, L. 2005. Treadmill exercise rehabilitation improves ambulatory function and cardiovascular fitness in patients with chronic stroke: a randomized, controlled trial. Stroke; 36(10):2206-2211.

Macko, R.F., Smith, G.V., Dobrovolny, C.L., Sorkin, J.D., Goldberg, A.P. and Silver, K.H. 2001. Treadmill training improves fitness reserve in chronic stroke patients. Arch Phys Med Rehabil; 82: 879-884.

Mead, G.E., Greig, C.A., Cunningham, I., Lewis, S.J., Dinan, S. and Saunders, D.H. 2007. Stroke: a randomised trial of exercise or relaxation. Journal of the American Geriatrics Society; 55:892-9.

Mudge, S., Barber, P.A. and Stott, N.S. 2009. Circuit-based rehabilitation improves gait endurance but not usual walking activity in chronic stroke: a randomized controlled trial. Archives of Physical Medicine and Rehabilitation;90(12):1989-96.

Olawale OA, Jaja SI, Anigbogu CN, Appiah-Kubi KO, and Jones-Okai D 2011.Exercise training improves walking function in an African group of stroke survivors: a randomized controlled trial.Clinical Rehabilitation 25: 442-450

Pang, M., Eng, J., Dawson, A., McKay, H. and Harris, J. 2005. A community-based fitness and mobility exercise program for older adults with chronic stroke: a randomised controlled trial. Journal of the American Geriatrics Society;53:1667-74.

Patterson, S.L., Forrester, L.W., Rodgers, M.M., Ryan, A.S., Ivey, F.M. and Sorkin, J.D. 2007. Determinants of walking function after stroke: differences by deficit severity. Archives of Physical Medicine and Rehabilitation;88(1):115-9.

Pohl, M., Mehrholz, J., Ritschel, C. and Ruckriem, S. 2002. Speed-dependent treadmill training in ambulatory hemiparetic stroke patients. A randomized controlled trial. Stroke; 33:553-558.

Potempa, K., Lopez, M., Braun, L.T., Szidon, J.P., Fogg, L., Tincknell, T. 1995. Physiological outcomes of aerobic exercise training in hemiparetic stroke patients. Stroke; 26(1):101-5.

Rensink, M., Schuurmans, M., Lindeman, E. and Haf-steinsdo, T. 2009. Task-oriented training in rehabilitation after stroke: systematic review.Journal of Advanced Nursing; 65(4):737-754.

Teasell, R. and Hussein, N. 2014. Stroke Rehabilitation Clinician Handbook. pp.1-20. Available @www.ebrsr.com. Retrieved on 10/01/2016.

Salbach, N., Mayo, N., Higgins, J., Ahmed, S., Finch, L. and Richards, C. 2001. Responsiveness and predictability of gait speed and other disability measures in acute stroke. Archives of PhysicalMedicine and Rehabilitation;82(9):1204-12.

Salbach, N.M., Mayo, N.E., Wood-Daphinee, S., Hanley, J.A. and Richard, C.L. 2004. A task-oriented intervention enhances walking distance and speed in the first year post stroke. A randomized controlled trial. Clinical Rehabilitation; 18: 509519. 


\section{Journal of Exercise Science \& Physiotherapy, Vol. 12, No. 2, 2016}

ISSN: 0973-2020 (Print)

ISSN: 2454-6089 (Online)

Saunders, D.H., Greig, C.A., Mead, G.E. and Young, A. 2009. Physical fitness training for stroke patients. Cochrane Database of Systematic Reviews; DOI: 10.1002/14651858.CD003316.pub3.

Saunders, D.H., Greig, C.A., Young, A and Mead, G.E. 2008. Association of activity limitations and lower-limb explosive extensor power in ambulatory people with stroke. Archives of Physical Medicine and Rehabilitation;89(4):677-83.

Saunders, D.H., Greig, C.A., Young, A. and Mead, G.E. 2004. Physical fitness training for stroke patients. Cochrane Database of Systematic Reviews; DOI: 10.1002/14651858.CD003316.pub2.

Saunders, DH., Sanderson, M., Brazzelli, M., Greig, C.A. and Mead, G.E. 2013. Physical fitness training for stroke patients. Cochrane Database of Systematic Reviews; CD003316. DOI: 10.1002/14651858.CD003316.pub5.

Sims, J., Galea, M., Taylor, N., Dodd, K., Jespersen, S. and Joubert, L. 2009.Regenerate: assessing the feasibility of a strength- training programme to enhance the physical and mental health of chronic post stroke patients with depression. International Journal of Geriatric Psychiatry;24(1): 76-83.

Smith, A.C., Saunders, D.H. and Mead, G. (2012), Cardiorespiratory fitness after stroke: a systematic review. International Journal of Stroke; 7:499-510.

Toledano-Zarhi, A., Tanne, D., Carmeli, E. and Katz-Leurer, M. 2011. Feasibility, safety and efficacy of an early aerobic rehabilitation program for patients after minor ischemic stroke: a pilot randomized controlled trial. Neurorehabilitation;28(2):85-90.

Van de Port, I.G.L., Wevers, L.E.G., Lindeman, E. and Kwakkel, G.2012. Effects of circuit training as alternative to usual physiotherapy after stroke: A randomised controlled trial. $B M J ; 344, \mathrm{e} 2072$.

van Peppen, R., Kwakkel, G., Wood-Dauphinee, S., Hendriks, H., Van der Wees, P., Dekker, J. 2004. The impact of physical therapy on functional outcomes after stroke: what's the evidence? Clinical Rehabilitation;18:833-62.

Wevers, L., van de Port, I., Vermue, M., Mead, G. and Kwakkel, G. 2009. Effects of a task-oriented circuit class training on walking competency after stroke. Stroke;40:2450-9.

Yocheved, L., Dickstein, R., Yael, C. and Marcovitz, E. 2001. The effect of treadmill training on the ambulation of stroke survivors in the early stages of rehabilitation: A randomized study. Journal of Rehabilitation Research and Development; 38(1):69-78.

Conflict of Interest: None declared 


\title{
A Study on Body Composition and Hand Grip Strength of Junior Free Style Wrestlers
}

\author{
Parwinder Singh and Ashok Kumar
}

\begin{abstract}
Aim: The aim of this study was to examine the body composition and hand grip strength of different weight categories of junior free style male wrestlers. Method: one hundred fifty $(\mathrm{N}=150)$ male junior free style wrestlers were participated as subjects and they were further divided into five groups according to their weight categories, each group was comprised of thirty wrestlers. Body fat percentage was estimated by using Durnin and Womersley equation and the strength was measured from hand grip test. Results: A statistical significant positive correlation was found between the hand grip strength and age, height, weight, BMI, skinfold thickness and $\% \mathrm{BF}$. Conclusion: it is concluded that the free style wrestling is a weight classified sport; therefore the correlation of weight of the wrestlers with strength is important. The results of the present study also demonstrated the effect of age, height, BMI, and $\mathrm{BF} \%$ on the hand grip strength of wrestlers.
\end{abstract}

Parwinder Singh, Ph.D Student, Department of Sports Science, Punjabi University Patiala (Punjab) India Ashok Kumar, Associate Professor, Department of Sports Science, Punjabi University Patiala (Punjab) India E-mail:akashokin@gmail.com
Key Words: Free Style, Wrestling, Skinfold, Anthropometry, Strength, Fat Percentage

DOI: $10.18376 /$ jesp/2016/v12/i2/111260

\section{Introduction}

A sport of wrestling has a strong tradition that precedes the first Olympic festival in 776 B. C., when Zeus wrestled Kronas for the possession of the earth (Gallagher, 1951). Since then the sport of wrestling continues to grow in popularity because of the discipline and mental toughness it requires to be successful in the sport. Unfortunately, the sport has also been associated with the stigma of "cutting weight" and the practices that accompany the process of competing at designated weight classes. Like the sports of judo, boxing, and competitive weight lifting, wrestling requires its athletes to compete at specific weights or weight classifications. Typically, these weight classifications differ by approximately 7-11 pounds depending on age and style of wrestling. It is common knowledge in present day of wrestling that wrestlers compete in weight classes below their "normal" weight. The purpose of this practice is to gain advantages in strength, speed, and leverage over their opponents (Steen \& Brownell, 1990). The changes in regulation of wrestling have forced several modifications in the fitness requirements of successful wrestlers, which as a result caused an evolution in the training methods (Yoon 2002; Horswill 1992; Sharratt et. al., 1986).Wrestling has been described as an intermittent physical event which produces great strength and muscle power demands of both the upper and lower body (Hubner-Wozniak et. al. 2004; Kraemer et. al. 


\section{Journal of Exercise Science \& Physiotherapy, Vol. 12, No. 2, 2016 ISSN: 0973-2020 (Print) \\ ISSN: 2454-6089 (Online)}

2001; Horswill et. al. 1992 \& 1989; Sharratt et. al. 1986).They generally want to minimize the body fat level and the total body weight without losing their body strength and power (Yoon, 2002). However, no relation was shown between the percentage of fat mass (\%FM) and the level of wrestling success (Yoon, 2002; Horswill 1992). The aim of the present study was to observe the body composition and hand grip strength in different weight categories of junior free style wrestlers. The present investigation was to study the relationship of body composition and hand grip strength in different weight categories of junior free style wrestlers.

\section{Material and Methods}

The study was conducted on 150 male junior free style wrestlers (age between 18-20 years) of five different groups i.e. Group 1- 46-50 kg junior free style wrestlers, Group 2$55 \mathrm{~kg}$ junior free style wrestlers, Group 3- $60 \mathrm{~kg}$ junior free style wrestlers, Group 4 $66 \mathrm{~kg}$ junior free style wrestlers, Group $5-74 \mathrm{~kg}$ junior free style wrestlers. The aim of the study was explained to each participant and signed informed consent was obtained from the participants. The body composition of junior free style wrestlers was estimated as per the method described by Durnin and Womersley (1974). BMI can be categorized according to the WHO (Laquatra, 2004). The handgrip strength of the dominant hands was evaluated using a handgrip dynamometer. The test was performed in the standing position. The subject held the dynamometer in the hand to be tested with the arm at right angles and the elbow by the side of the body. Subject was then asked to squeeze the dynamometer with his maximum isometric effort for a $5 \mathrm{sec}$ period. Test was repeated two times with both hands. The 30 second rest interval was provided between measurements and the highest score was recorded. The results of five groups have been compared with each other. Karl Pearson's coefficient of correlation was used to find the relationship among age, weight, BMI, body composition and handgrip strength variables of free style junior wrestler in five groups according to their weight. To determine the differences between the mean of the various variables among different groups, one way Analysis of Variance (ANOVA) was used. Scheffe Post Hoc test was also used to identify the location of significant differences among the different groups. The level of significance was $\mathrm{p}<0.05$.

Table 1. Mean \pm SD of age, height, weight, BMI, \% body fat, right hand grip, left hand grip of different groups

\begin{tabular}{|c|c|c|c|c|c|c|}
\hline Variable(s) & $\begin{array}{c}\text { Group 1 } \\
(n=30)\end{array}$ & $\begin{array}{c}\text { Group } 2 \\
(n=30)\end{array}$ & $\begin{array}{c}\text { Group 3 } \\
(n=30)\end{array}$ & $\begin{array}{c}\text { Group } 4 \\
(n=30)\end{array}$ & $\begin{array}{c}\text { Group } 5 \\
(n=30)\end{array}$ & $\begin{array}{c}\text { Total } \\
(n=150)\end{array}$ \\
\hline Age (year) & $\begin{array}{c}18.13 \pm 0 \\
77\end{array}$ & $\begin{array}{c}18.73 \pm 0.6 \\
9\end{array}$ & $18.53 \pm 0.68$ & $18.50 \pm 0.68$ & $18.67 \pm 0.47$ & $\begin{array}{c}18.51 \pm .0 .6 \\
5\end{array}$ \\
\hline Height (cm) & $\begin{array}{c}166.69 \pm . \\
2.62\end{array}$ & $\begin{array}{c}168.00 \pm .2 \\
62\end{array}$ & $\begin{array}{c}168.46 \pm .3 \\
24\end{array}$ & $\begin{array}{c}168.95 \pm .2 \\
79\end{array}$ & $\begin{array}{c}171.80 \pm 4.3 \\
7\end{array}$ & $\begin{array}{c}168.78 \pm .3 \\
12\end{array}$ \\
\hline Weight(kg) & $\begin{array}{c}51.50 \pm .1 \\
33\end{array}$ & $\begin{array}{c}55.70 \pm .1 .4 \\
1\end{array}$ & $61.50 \pm 0.88$ & $\begin{array}{c}66.33 \pm .1 .4 \\
0\end{array}$ & $74.25 \pm 3.22$ & $61.85 \pm 1.64$ \\
\hline BMI & $\begin{array}{c}18.54 \pm 0 \\
65\end{array}$ & $19.74 \pm .77$ & $21.69 \pm 0.90$ & $23.25 \pm 0.85$ & $25.18 \pm 1.43$ & $21.68 \pm 0.92$ \\
\hline \% Bodyfat & $\begin{array}{c}9.10 \pm 1.6 \\
7\end{array}$ & $\begin{array}{c}10.32 \pm 2.1 \\
3\end{array}$ & $11.92 \pm 1.43$ & $12.71 \pm 2.28$ & $14.88 \pm 3.06$ & $11.78 \pm 2.11$ \\
\hline $\begin{array}{l}\text { Right hand } \\
\text { grip (Kg) }\end{array}$ & $\begin{array}{c}43.13 \pm 6 \\
579\end{array}$ & $\begin{array}{c}44.16 \pm 4.8 \\
42\end{array}$ & $\begin{array}{c}45.53 \pm 2.81 \\
2\end{array}$ & $\begin{array}{c}49.73 \pm 6.75 \\
6\end{array}$ & $\begin{array}{c}56.50 \pm 5.67 \\
3\end{array}$ & $47.81 \pm 5.32$ \\
\hline $\begin{array}{l}\text { Left hand } \\
\text { grip (Kg) }\end{array}$ & $\begin{array}{c}39.36 \pm 6 \\
299\end{array}$ & $\begin{array}{c}41.30 \pm 6.0 \\
06\end{array}$ & $\begin{array}{c}43.60 \pm 3.95 \\
3\end{array}$ & $\begin{array}{c}47.26 \pm 6.90 \\
7\end{array}$ & $\begin{array}{c}53.83 \pm 6.30 \\
3\end{array}$ & $45.07 \pm 5.88$ \\
\hline
\end{tabular}




\section{Results}

Table 1 shows that the mean age of group1, group2, group3, group4 and group5 was $18.13 \pm .77$ year, $18.73 \pm .69$ year, $18.53 \pm .68$ year, $18.50 \pm .68$ year and $18.67 \pm .47$ year. The mean height of the subjects of group1, group2, group3, group4 and group5 was $166.69 \pm .2 .62 \mathrm{~cm}$ year, $168.00 \pm .2 .62 \mathrm{~cm}, 168.46 \pm .3 .24 \mathrm{~cm}, 168.95 \pm .2 .79 \mathrm{~cm}$ and $171.80 \pm 4.37 \mathrm{~cm}$. The mean weight of the subjects of group1, group2, group3, group4 and group5 was $51.50 \pm .1 .33 \mathrm{~kg}, 55.70 \pm .1 .41 \mathrm{~kg}, 61.50 \pm .88 \mathrm{~kg}, 66.33 \pm .1 .40 \mathrm{~kg}$ and $74.25 \pm 3.22 \mathrm{~kg}$. The mean body mass index of the subjects of group1, group2, group3, group4 and group5 was $18.54 \pm .65 \mathrm{Kg} / \mathrm{m}^{2}, \quad 19.74 \pm .77 \mathrm{Kg} / \mathrm{m}^{2}, \quad 21.69 \pm .90 \mathrm{Kg} / \mathrm{m}^{2}$, $23.25 \pm .85 \mathrm{Kg} / \mathrm{m}^{2}$ and $25.18 \pm 1.43 \mathrm{Kg} / \mathrm{m}^{2}$ respectively. The mean percent fat of the subjects of group1, group2, group3, group4 and group5 was $9.10 \pm 1.67 \%, 10.32 \pm 2.13 \%$, $11.92 \pm 1.43 \%, 12.71 \pm 2.28 \%$ and $14.88 \pm 3.06 \%$. The mean right hand grip of the subjects of group1, group2, group3, group4 and group5 was 43.133 $\pm 6.579,44.166 \pm 4.842$, $45.533 \pm 2.812,49.733 \pm 6.756$ and $56.500 \pm 5.673$. The mean left hand grip of the subjects of group1, group2, group3, group4 and group5 was 39.366 $\pm 6.299,41.300 \pm 6.006$, $43.600 \pm 3.953,47.266 \pm 6.907$ and $53.833 \pm 6.303$. Further, the analysis of variance (Table 2) revealed that the variance in the mean values of age, height, weight, BMI, \% body fat, right hand grip and left hand grip strength of junior free style wrestlers among different groups was statistical significant.

Table 2. Analysis of variance of age, height, weight, BMI, \% body fat, right and left hand grip strength among different groups

\begin{tabular}{lccccc}
\hline Variable(s) & Groups & Sum of Squares & Mean Square & F & Sig. \\
\hline Age & Between Groups & 6.50 & 1.627 & 3.63 & .008 \\
& Within Groups & 64.96 & .448 & & \\
\hline Height & Between Groups & 427.42 & 106.855 & 10.43 & .000 \\
& Within Groups & 1484.95 & 10.241 & & \\
\hline Weight & Between Groups & 9562.39 & 2390.600 & 706.97 & .000 \\
& Within Groups & 490.31 & 3.381 & & \\
\hline Body mass index & Between Groups & $\mathbf{8 4 9 . 9 4}$ & 212.485 & 230.09 & .000 \\
& Within Groups & 133.90 & .923 & & \\
\hline Percentage Fat & Between Groups & $\mathbf{5 9 4 . 5 7}$ & 148.644 & 30.86 & .000 \\
& Within Groups & 698.32 & 4.816 & & \\
\hline Right hand grip $(\mathrm{kg})$ & Between Groups & 3586.307 & $\mathbf{8 9 6 . 5 7 7}$ & 29.396 & .000 \\
& Within Groups & 4422.467 & 30.500 & & \\
\hline Left hand grip(kg) & Between Groups & 3915.693 & $\mathbf{9 7 8 . 9 2 3}$ & 27.368 & .000 \\
& Within Groups & $\mathbf{5 1 8 6 . 5 0 0}$ & 35.769 & & \\
\hline
\end{tabular}

*significant at the 0.05 level 
Table 3 shows a positive statistical significant relationship among percent body fat, height, and weight of combined $(\mathrm{N}=150)$ groups of junior free style wrestlers. A positive statistical significant relationship was also found between right and left hand grip strength and percent body fat, weight and BMI (Table 3).

Table 3. Correlation among age, height, weight, BMI, \% body fat, right hand grip, left hand grip variables of combined group $(\mathrm{N}=150)$

\begin{tabular}{|c|c|c|c|c|c|c|}
\hline Variable(s) & Height & weight & $\begin{array}{l}\text { Body } \\
\text { mass } \\
\text { index }\end{array}$ & $\begin{array}{l}\text { Percentage } \\
\text { fat }\end{array}$ & $\begin{array}{l}\text { Right } \\
\text { hand } \\
\text { grip }\end{array}$ & $\begin{array}{c}\text { Left } \\
\text { hand } \\
\text { grip }\end{array}$ \\
\hline Age & .076 & $.168^{*}$ & .160 & .080 & -.160 & -.122 \\
\hline Height & & $.483^{* *}$ & $.167^{*}$ & $.257^{* *}$ & $.188^{*}$ & .148 \\
\hline Weight & & & $.944^{* *}$ & $.722^{* *}$ & $.640^{* * *}$ & $.631^{* *}$ \\
\hline BMI & & & & $.717^{* *}$ & $.647^{* *}$ & $.654^{* *}$ \\
\hline $\begin{array}{l}\text { Percentage } \\
\text { fat }\end{array}$ & & & & & $.529^{* * *}$ & $.514^{* *}$ \\
\hline $\begin{array}{l}\text { Right } \\
\text { hand grip }\end{array}$ & & & & & & $.958^{* *}$ \\
\hline
\end{tabular}

\section{Discussion}

The results of the present study shows that the body fat percentage of the wrestlers of different groups were in the acceptable range according to the WHO (Laquatra, 2004). In other words, we can say no obesity was observed in different group of junior free style wrestlers. The maximum body fat percentage was observed in group 5 (higher weight category) and minimum in group1 (lower weight) wrestlers. Thus, a trend of increased in body fat percentage from lower body weight group $1(46 \mathrm{~kg}-50 \mathrm{~kg})$ to higher body weight group $5(74 \mathrm{~kg}$ ) of wrestlers was observed. The maximum lean body mass percentage was observed in group 1 and minimum lean body mass percentage was observed in group 5 . Thus, a trend of decrease in lean body mass percentage was observed from lower body weight group1 (46-50kg) to higher body weight group5 (74kg). Saygin (2014) also reported that the percentage body fat has different values in all three classes like lightweight, middle weight and heavy weight wrestlers. According to Saygin (2014) the maximum body fat was observed in heavyweight wrestlers when compared to lightweight wrestlers and middleweight wrestlers. Francihini et al. (2014) also reported that the highest skinfold thickness values were observed in heavyweight judo athletes as compared to lightweight and middleweight judo athletes, in other words, heavy weight judo athletes has more fat percentage than lightweight and middle weight. The mean value of various anthropometric variables body mass index was increased from lower 


\section{Journal of Exercise Science \& Physiotherapy, Vol. 12, No. 2, 2016 ISSN: 0973-2020 (Print) \\ ISSN: 2454-6089 (Online)}

body weight (group1) to higher body weight (group 5). Selda (2014) also reported that there was a significant difference in the body mass index of different weight categories of greco roman and free style wrestlers and the body mass index was higher in heavy weight greco roman and free style wrestlers as compared to the lower and middle weight greco roman and free style wrestlers. Selda (2014) reported that both heavy weight greco roman and free style group wrestlers was taller than the lower weight and middle weight wrestlers and a similar trend of body height was also found in the present study (i.e. junior free style wrestlers). The grip strength score of group5 wrestlers were more than the wrestlers of other groups. Further, the right hand grip strength score was more than left hand grip strength. Saygin (2014) showed that the hand grip strength were observed difference values in three weight classes of wrestlers in this study that values of hand grip strength were observed lower in the lightweight wrestlers when compared with the values of middleweight wrestlers and the values of heavyweight wrestlers. Right hand grip was observed stronger as compare to left hand grip. A significant difference was found in right handgrip and left hand grip strength among all groups of wrestlers $(p<0.05)$. Selda (2014) also reported that the heavy weight greco roman and the heavy weight freestyle wrestlers were found more strongest when compared with lower weight and the middle weight wrestlers.

\section{Conclusion}

From the results of the present study, it is concluded that the body fat percentage of the wrestlers of different groups was in the acceptable range i.e. obesity was not observed in them. Further, it is concluded that the wrestlers of lower body weight category (group1) were better in anthropometric variables than higher body weight category (group 5) like body fat percentage, body mass index. But (group5) were better in hand grip strength than lower body weight category (group 1) like right hand grip strength, left hand grip strength. A positive relationship was also observed between age, height, weight, BMI, \% body fat, right hand and left hand grip strength.

\section{References}

Durnin.JV. and Womersley J.(1974).Body fat assessed from total body density and its estimation from skinfold thickness: measurements on 481 males and females aged from 16 to 72 years. Br J Nutr, 32:77-97.

Franchini Emerson, Katarzyna Sterkowicz-Przybycien and Monica Yuri Takito. (2014).Anthropometrical Profile of Judo Athletes: Comparative Analysis between Weight Categories. Int. J. Morphol., 32(1):36-42.

Gallagher, E. C. (1951). Wrestling (Revised Edition ed.). New York: The Ronald Press Company.

Horswill C.A. (1992). Applied physiology of amateur wrestling.Sports Med 14:114-143.

Horswill C.A., Miller J.E., Scott J.R., Smith C.M., Welk G., Von Handel P.(1992). Anaerobic and aerobic power in arms and legs of elite senior wrestlers Int $\mathbf{J}$ Sports Med, 13, 558-561.

Horswill C.A., Scott J.R., Galea P.(1989). Comparison of maximum aerobic power, maximum anaerobic power, and skinfold thickness of elite and nonelite junior wrestlers.Int J Sports Med 10:165-168. 
HubnerWozniak E., Kosmol A., Lutoslawska G., Bem E.Z. (2004).Anaerobic performance of arms and legs in male and female free style wrestlers. J Sci Med Sport 7:473-480.

Kraemer W.J., Fry AC, Rubin M.R., Triplett-mcbride T., Gordon S.E., Koziris L.P., Lynch J.M., Volek J.S., Meuffels D.E., Newton R.U., Fleck S.J. (2001). Physiological and performance responses to tournament wrestling. Med Sci Sports Exerc 33:1367-1378.

Laquatra I. (2004). Nutrition for weight management. In Krause,,s Food, Nutrition, and Diet Therapy. Ed. by Mahan, L.K. and Escott-Stumps, S. 11th ed. Saunders Company, Philadelphia, Pennsylvanian, pp. 558-593.

Saygin O. (2014). Examination of Some Physical, Hematological Parameters and Iron Status of Greco-Roman Wrestlers in the Age Category of Cadets by Weight Classes Anthropologist 18(2): 325-334.

Selda Basara, IremDuzguna, Nevin Atalay Guzela, Ibrahim Cicioglub and Bulent Çelikc (2014) Differences in strength, flexibility and stability in freestyle and GrecoRoman wrestlers. Musculoskeletal Rehabilitation 27 321-330.

Sharratt M.T., Taylor A.W., Song T.M. (1986). A physiological profile of elite Canadian freestyle wrestlers. Can J Appl Sport Sci 11:100-105.

Steen, S. N., \& Brownell, K. D.(1990). Patterns of weight loss and regain in wrestlers: has the tradition changed. Med Sci Sports Exercise, 22(6), 762-768.

Yoon J. (2002). Physiological profiles of elite senior wrestlers. Sports Med 32:225-233.

Conflict of Interest: None Declared 


\title{
Effect of Isometric Strength Training on Blood Pressure: Systematic Review of Literature with Specific Emphasis on Indians
}

\author{
Sonu Punia, Sivachidambaram Kulandaivelan and Vandana Punia
}

\begin{abstract}
Aim: To systematically review and report the articles on isometric exercise on blood pressure. Method: Study was done on February 2016 in Google Scholar using search terms 'Isometrics' and 'Blood pressure' AND 'India'. 420 articles were initially identified and after inclusion, exclusion criteria 3 articles are used for this review. Results: Studies were at least 5 weeks duration with $30 \%$ MVIC (maximum voluntary isometric contraction) of intensity for $3 \mathrm{~min}$ duration. Total of 110 subjects participated with median of 30 subjects. Garg et al. (2014) found mean difference (MD) of -9.87 $\mathrm{mmHg}$ in SBP and $-5.26 \mathrm{mmHg}$ in DBP. Sandhu et al. (2014) found MD of $-7.04 \mathrm{mmHg}$ in SBP and $-6.56 \mathrm{mmHg}$ in DBP. Gandhi (2016) found MD of $-3.24 \mathrm{mmHg}$ in SBP and $-4.03 \mathrm{mmHg}$ in DBP. Overall there was a mean reduction of $6.72 \mathrm{mmHg}$ in SBP and 5.28 $\mathrm{mmHg}$ in DBP. Conclusion: After isometric exercise in Indians BP reduction is as of Western counterparts.
\end{abstract}

Sonu Punia,Assistant Professor, Department of Physiotherapy, GJUST, Hisar (Haryana) India

Sivachidambaram Kulandaivelan Assistant Professor, Department of Physiotherapy, GJUST, Hisar (Haryana) India

E-mail: tryhard2024@yahoo.co.in

Vandana Punia, Associate Professor, HRDC, GJUST,

Hisar (Haryana) India
Key Words: Hand grip, Isometrics, Post exercise hypotension

DOI: $10.18376 / j e s p / 2016 / v 12 / \mathbf{i} / 111261$

\section{Introduction}

High blood pressure (BP) is ranked as the third most important risk factor for burden of disease in south Asia (Lim et al., 2012). Overall prevalence for hypertension in India was $29.8 \%$. Significant differences in hypertension prevalence were noted between rural and urban parts [27.6\% and 33.8\%]. Of these, $25 \%$ rural and $42 \%$ urban Indians are aware of their hypertensive status. Only $25 \%$ rural and $38 \%$ of urban Indians are being treated for hypertension. One-tenth of rural and one-fifth of urban Indian hypertensive population have their BP under control (Anchala et al., 2014). Studies reported on the risk factors associated with HTN in Indians include age, alcohol, smoking and chewing tobacco, BMI, central obesity (defined as waist circumference $>90 \mathrm{~cm}$ in men and $>80 \mathrm{~cm}$ in women), consumption of low vegetables/fruits, high consumption of dietary fat and salt, and physical inactivity (Laxmaiah et al., 2015; Anchala et al., 2014). Antihypertensive therapy alone has failed to reduce blood pressure to greater extent. Hence, life style modification is the first line treatment of choice in high normal or stage I hypertensive patients. Promoting physical activity, quitting the smoking, alcohol reduction, salt reduction in diet, stress reduction are some of the life style modifications that proven to reduce blood pressure (Vandana et al., 2016). Exercises are better than pharmacological 


\section{Journal of Exercise Science \& Physiotherapy, Vol. 12, No. 2, 2016 ISSN: 0973-2020 (Print) \\ ISSN: 2454-6089 (Online)}

treatment as they don't have any known side effects and they are cheap, easy to administer. There are four main types of exercises that reduce the blood pressure to the extent of pharmacological interventions. They are physical activity such as walking, cycling etc., aerobic exercise, resistance exercise and isometric exercise (Kulandaivelan et al., 2016). Isometric hand grip exercise, a form of simple, static resistance exercise, has shown to reduce blood pressure to the greater extent than that of other forms of exercise. A recent meta-analytical study that compares all forms of exercise concluded that isometric exercise is the best form of exercise to contain the blood pressure (Cornelissen and Smart, 2013). These meta-analytical studies are mainly based on western population. In India, very few studies have been done to investigate the effect of exercise, aerobics, resistance and isometric, on blood pressure. Thus the primary objective of present review was to see the effect of isometric exercise on blood pressure in Indian population. Then to compare these results with international studies.

\section{Materials \& Method}

This review was done between January and February, 2016. We comprehensively searched 'Google Scholar' search engine for relevant articles. The following search terminology was used to identify articles: "Isometric Exercise" AND "Blood Pressure" AND "India". 420 articles were identified in Google Scholar. Inclusion criteria for the selection of the present review are full text articles in English; intervention should be of at least 4 weeks; articles should be from India; subjects should be either normotensive or hypertensive individuals. Animal studies, review articles, subjects with other pathological condition were excluded. Studies using intervention other than isometric exercise were excluded. 3 articles met the inclusion criteria. In order to compare our results with international studies, we selected 4 meta-analytical studies (Carlson et al., 2014; Cornelissen and Smart, 2013; Kelley and Kelley, 2010; Owen et al., 2010). We selected all articles included in these meta-analyses for our review. Total 10 articles were identified and we could find only 8 full text articles. We screened references of 8 full text articles for further articles related to isometric training on blood pressure. We identified 9 more articles ( 8 articles with full text). We included 5 articles which showed changes in SBP and DBP values after isometric training. Overall 13 articles, 18 study groups, included in this review (7 articles from Canada, 4 articles from UK and 2 articles from US; 8 articles from normotensives [10 study groups] and 5 articles from hypertensive [8 study groups] patients).

420 references selected

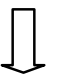

7 were selected

4 were excluded because of one time study

3 selected based on inclusion criteria

Figure 1. Schematic diagram of search methodology in Google Scholar 


\section{Journal of Exercise Science \& Physiotherapy, Vol. 12, No. 2, 2016 ISSN: 0973-2020 (Print) \\ ISSN: 2454-6089 (Online)}

\section{Results}

Isometric exercise is a type of exercise in which the contraction of muscle occurs without change in length of muscles. It is type of static exercise in which muscles contract without any movement at joint. We selected total of 3 articles with 140 normotensive subjects for this review. All the 3 articles are from northern India, 2 from Uttar Pradesh and 1 from Himachal Pradesh. All articles are recent one, at least 2014 or latter. Garg et al., 2014 investigated the effects of isometric exercise training on resting blood pressure in 30 normal adults aged 20-40 years. Isometric hand grip exercise training protocol consisted of five 3- min bouts of exercise at 30\% MVC (Maximum Voluntary Contraction) separated by 5 minute rest periods. Exercise was performed 3 times per week for 10 weeks. There was a significant reduction in resting blood pressure following 10 weeks of exercise training. SBP reduced from $122.67 \mathrm{mmHg}$ to $112.8 \mathrm{mmHg}$ and DBP reduced from $81.73 \mathrm{mmHg}$ to $76.47 \mathrm{mmHg}$. They found mean difference (MD) of $9.87 \mathrm{mmHg}$ for SBP and $-5.26 \mathrm{mmHg}$ for DBP. Sandhu et al., 2014 evaluated the effect of isometric exercise training on blood pressure in 50 normotensive individuals aged 1935 years. Isometric handgrip training was imparted to 25 individuals for 8 weeks with increment in intensity every 2 week. They stated that after 2 weeks of training results was non-significant but after 6 and 8 weeks of training, there was a significant reduction in both SBP as well as DBP in experimental group as compared to control group. They found MD of $-7.04 \mathrm{mmHg}$ in SBP and $-6.56 \mathrm{mmHg}$ in DBP. Gandhi 2016 studied the effect of isometric hand grip exercise training of 5 weeks on cardiovascular and echocardiographic parameters among healthy males. Subjects were asked to perform 4 isometric handgrip exercises at $30 \%$ of MVC for 3 minutes with 5 minutes rest in between. The frequency of exercise was 4 days per week for a period of 5 weeks. Cardiovascular parameters were recorded at the start (pre) and at the end (post) of the training. Resting SBP reduced from 108.97 to $105.73 \mathrm{mmHg}$ (MD $-3.24 \mathrm{mmHg}$ ) and DBP reduced from 69.03 to $65.00 \mathrm{mmHg}$ (MD $-4.03 \mathrm{mmHg}$ ).International studies reported mean reduction of $7.14 \mathrm{mmHg}$ in SBP and $2.74 \mathrm{mmHg}$ in DBP $(\mathrm{n}=18)$. Hypertensive patients showed more reduction in SBP than normotensive subjects (7.76 $\mathrm{mmHg}$ Vs $6.65 \mathrm{mmHg}$ for hypertensive, normotensive subjects respectively). However, there was no such difference in DBP values $(2.71 \mathrm{mmHg} \mathrm{Vs} 2.77 \mathrm{mmHg}$ for hypertensive, normotensive subjects respectively). Majority of the included studies were 8 weeks in duration (13 out of 18 study groups). They reported a mean reduction of 6.92 in SBP and 2.15 in DBP. There was no association between duration of intervention and $\mathrm{BP}$ reduction. Hand grip exercise seems to be superior to that of leg press exercise in hypertensive subjects (Howden et al., 2002). 3 sessions per week is superior to that of 5 sessions per week (Badrov et al., 2013a) and followed by most of the studies. 
Journal of Exercise Science \& Physiotherapy, Vol. 12, No. 2, 2016 ISSN: 0973-2020 (Print) ISSN: 2454-6089 (Online)

Table 1. Summary of isometric exercise training on blood pressure

\begin{tabular}{|c|c|c|c|c|c|c|}
\hline $\begin{array}{l}\text { Author } \\
\text { Year }\end{array}$ & $\begin{array}{l}\text { Type of study } \\
\text { Sample size } \\
\text { Duration }\end{array}$ & $\begin{array}{l}\text { Pre } \\
\text { SBP } \\
(\mathbf{m m} \\
\mathbf{H g})\end{array}$ & $\begin{array}{l}\text { Post SBP } \\
(\mathrm{mmHg})\end{array}$ & $\begin{array}{l}\text { Pre DBP } \\
(\mathrm{mmHg})\end{array}$ & $\begin{array}{l}\text { Post DBP } \\
(\mathrm{mmHg})\end{array}$ & $\begin{array}{l}\text { Mean } \\
\text { Difference } \\
\text { (MD) } \\
\text { mmHg } \\
\end{array}$ \\
\hline \multicolumn{7}{|c|}{ Indians } \\
\hline $\begin{array}{l}\text { Sandhu et } \\
\text { al., } 2014\end{array}$ & $\begin{array}{l}\text { Experimental study } \\
50 \text { normotensives } \\
8 \text { Weeks }\end{array}$ & $\begin{array}{l}112.0 \\
8 \pm \\
4.45\end{array}$ & $\begin{array}{l}105.04 \pm \\
4.55\end{array}$ & $\begin{array}{l}70.64 \pm \\
4.95\end{array}$ & $\begin{array}{l}64.08 \pm \\
4.43\end{array}$ & $\begin{array}{l}\text { SBP -07.04 } \\
\text { DBP -06.56 }\end{array}$ \\
\hline $\begin{array}{l}\text { Garg et al } \\
, 2014\end{array}$ & $\begin{array}{l}\text { Experimental study } \\
30 \text { healthy adults } \\
10 \text { Weeks }\end{array}$ & $\begin{array}{l}122.6 \\
7 \pm \\
2.31\end{array}$ & $\begin{array}{l}112.8 \pm \\
1.86\end{array}$ & $\begin{array}{l}81.73 \pm \\
2.66\end{array}$ & $\begin{array}{l}76.47 \pm \\
3.00\end{array}$ & $\begin{array}{l}\text { SBP -09.87 } \\
\text { DBP - } 05.26\end{array}$ \\
\hline $\begin{array}{l}\text { Gandhi, } \\
2016\end{array}$ & $\begin{array}{l}\text { Experimental study } \\
30 \text { healthy males } \\
5 \text { Weeks }\end{array}$ & $\begin{array}{l}108.9 \\
7 \pm \\
7.29\end{array}$ & $\begin{array}{l}105.73 \pm \\
6.83\end{array}$ & $\begin{array}{l}69.03 \pm \\
5.99\end{array}$ & $\begin{array}{l}65.00 \pm \\
6.74\end{array}$ & $\begin{array}{l}\text { SBP -03.24 } \\
\text { DBP -04.03 }\end{array}$ \\
\hline \multicolumn{7}{|c|}{ Internationals } \\
\hline $\begin{array}{l}\text { Ray and } \\
\text { Carrasco, } \\
2000\end{array}$ & $\begin{array}{l}\text { Experimental Study } \\
24 \text { normotensives } \\
5 \text { Weeks }\end{array}$ & $\begin{array}{l}116.0 \\
0 \pm \\
3.00\end{array}$ & $\begin{array}{l}113.00 \pm \\
2.00\end{array}$ & $\begin{array}{l}86.00 \pm \\
1.00\end{array}$ & $\begin{array}{l}82.00 \pm \\
1.00\end{array}$ & $\begin{array}{l}\text { SBP }-03.00 \\
\text { DBP }-04.00\end{array}$ \\
\hline $\begin{array}{l}\text { Howden } \\
\text { et al., } \\
2002\end{array}$ & $\begin{array}{l}\text { Experimental Study } \\
27 \text { subjects } \\
\text { T1 and T2* } \\
5 \text { Weeks each }\end{array}$ & $\begin{array}{l}\text { T1 } \\
120.7 \\
\pm 9.6 \\
\text { T2 } \\
114.3 \\
\pm 11.3\end{array}$ & $\begin{array}{l}\text { T1 } \\
110.7 \pm 8.4 \\
\text { T2 } \\
101.9 \pm 7.7\end{array}$ & $\begin{array}{l}\text { T1 } 70.3 \\
\pm 7.4 \\
\text { T2 } 64.8 \\
\pm 5.6\end{array}$ & $\begin{array}{l}\mathrm{T} 1 \\
66.7 \pm 11.2 \\
\mathrm{~T} 2 \\
58.8 \pm 12.3\end{array}$ & $\begin{array}{l}\text { SBP T1 - } \\
10.0 \\
\text { T2 -13.4 } \\
\text { DBP T1 - } \\
03.6 \\
\text { T2 -06.0 }\end{array}$ \\
\hline $\begin{array}{l}\text { McGowan } \\
\text { et al., } \\
2007 \mathrm{a}\end{array}$ & $\begin{array}{l}\text { Experimental Study } \\
11 \text { subjects } \\
8 \text { Weeks }\end{array}$ & $\begin{array}{l}118.1 \\
\pm 2.4\end{array}$ & $\begin{array}{l}113.2 \pm \\
1.3\end{array}$ & $\begin{array}{l}64.2 \pm \\
2.2\end{array}$ & $64.1 \pm 1.2$ & $\begin{array}{l}\text { SBP -04.90 } \\
\text { DBP }-00.10\end{array}$ \\
\hline $\begin{array}{l}\text { McGowan } \\
\text { et al., } \\
2007 \mathrm{~b}\end{array}$ & $\begin{array}{l}\text { Experimental Study } \\
16 \text { hypertensives } \\
8 \text { Weeks }\end{array}$ & $\begin{array}{l}\text { Uni } \\
141.6 \\
\pm 3.8 \\
\mathrm{Bi} \\
133.9 \\
\pm 5.0\end{array}$ & $\begin{array}{l}\text { Uni } \\
132.4 \pm 4.4 \\
\mathrm{Bi} \\
118.5 \pm 4.0\end{array}$ & $\begin{array}{l}\text { Uni } \\
79.6 \pm 3.8 \\
\mathrm{Bi} \\
73.2 \pm 3.2\end{array}$ & $\begin{array}{l}\text { Uni } \\
76.0 \pm 3.1 \\
\mathrm{Bi} \\
67.2 \pm 3.4\end{array}$ & $\begin{array}{l}\text { SBP } \\
\text { Uni -09.20 } \\
\text { Bi - } 15.40 \\
\text { DBP } \\
\text { Uni -03.60 } \\
\text { Bi -06.00 }\end{array}$ \\
\hline $\begin{array}{l}\text { Millar et } \\
\text { al., } 2008\end{array}$ & $\begin{array}{l}\text { Experimental Study } \\
49 \text { normotensives } \\
8 \text { Weeks }\end{array}$ & $\begin{array}{l}122.0 \\
\pm 3.0\end{array}$ & $\begin{array}{l}112.0 \pm \\
3.0\end{array}$ & $\begin{array}{l}70.0 \pm \\
1.0\end{array}$ & $67.0 \pm 1.0$ & $\begin{array}{l}\text { SBP }-10.00 \\
\text { DBP }-03.00\end{array}$ \\
\hline $\begin{array}{l}\text { Wiles et } \\
\text { al., } 2010\end{array}$ & $\begin{array}{l}\text { Experimental Study } \\
33 \text { healthy males } \\
\text { HI and LI } 8 \text { Weeks }\end{array}$ & $\begin{array}{l}\text { HI } \\
121.5 \\
\pm 4.6 \\
\text { LI } \\
118.0 \\
\pm 10.1 \\
\end{array}$ & $\begin{array}{l}\text { HI } \\
116.3 \pm 6.9 \\
\text { LI } \\
114.3 \pm 8.6\end{array}$ & $\begin{array}{l}\text { HI } 68.5 \\
\pm 4.6 \\
\text { LI } 69.6 \pm \\
9.7\end{array}$ & $\begin{array}{l}\text { HI } 65.8 \pm \\
3.2 \\
\text { LI } 67.1 \pm \\
8.3\end{array}$ & $\begin{array}{l}\text { SBP } \\
\text { HI -05.20 } \\
\text { LI -03.70 } \\
\text { DBP } \\
\text { HI -02.70 } \\
\text { LI -02.50 } \\
\end{array}$ \\
\hline $\begin{array}{l}\text { Devereux } \\
\text { et al., } \\
2011\end{array}$ & $\begin{array}{l}\text { Experimental Study } \\
13 \text { normotensives } \\
4 \text { Weeks }\end{array}$ & $\begin{array}{l}119.9 \\
\pm 11.6\end{array}$ & $\begin{array}{l}115.0 \pm \\
11.5\end{array}$ & $\begin{array}{l}69.0 \pm \\
4.4\end{array}$ & $66.2 \pm 5.0$ & $\begin{array}{l}\text { SBP }-04.90 \\
\text { DBP }-02.80\end{array}$ \\
\hline $\begin{array}{l}\text { Baross et } \\
\text { al., } 2012\end{array}$ & $\begin{array}{l}\text { Experimental Study } \\
30 \text { middle aged men } \\
\text { HI and LI } 8 \text { Weeks }\end{array}$ & $\begin{array}{l}\text { HI } \\
138.7 \\
\pm 7.0 \\
\text { LI }\end{array}$ & $\begin{array}{l}\text { HI } \\
127.9 \pm 8.0 \\
\text { LI } \\
136.5 \pm 5.9\end{array}$ & $\begin{array}{l}\text { HI } \\
78.2 \pm 5.5 \\
\text { LI } \\
78.3 \pm 5.5\end{array}$ & $\begin{array}{l}\text { HI } \\
76.6 \pm 7.4 \\
\text { LI } \\
79.4 \pm 5.6\end{array}$ & $\begin{array}{l}\text { SBP } \\
\text { HI }-10.80 \\
\text { LI }-0.80 \\
\text { DBP }\end{array}$ \\
\hline
\end{tabular}


Journal of Exercise Science \& Physiotherapy, Vol. 12, No. 2, 2016 ISSN: 0973-2020 (Print)

ISSN: 2454-6089 (Online)

\begin{tabular}{|c|c|c|c|c|c|c|}
\hline & & $\begin{array}{l}137.3 \\
\pm 5.3\end{array}$ & & & & $\begin{array}{l}\text { HI }-01.60 \\
\mathrm{LI}+01.10\end{array}$ \\
\hline $\begin{array}{l}\text { Millar et } \\
\text { al., } 2012\end{array}$ & $\begin{array}{l}\text { Experimental Study } \\
23 \text { hypertensives } \\
8 \text { Weeks }\end{array}$ & $\begin{array}{l}125 \pm \\
3\end{array}$ & $120 \pm 2$ & $73 \pm 2$ & $70 \pm 3$ & $\begin{array}{l}\text { SBP }-05.00 \\
\text { DBP }-03.00\end{array}$ \\
\hline $\begin{array}{l}\text { Stiller- } \\
\text { Moldovan } \\
\text { et al., } \\
2012\end{array}$ & $\begin{array}{l}\text { Experimental Study } \\
20 \text { hypertensives } \\
8 \text { Weeks }\end{array}$ & $\begin{array}{l}127.4 \\
\pm 10.1\end{array}$ & $\begin{array}{l}125.5 \pm \\
8.6\end{array}$ & $\begin{array}{l}76.0 \pm \\
6.0\end{array}$ & $74.4 \pm 6.0$ & $\begin{array}{l}\text { SBP -01.90 } \\
\text { DBP -01.60 }\end{array}$ \\
\hline $\begin{array}{l}\text { Badrov et } \\
\text { al., 2013a }\end{array}$ & $\begin{array}{l}\text { Experimental Study } \\
32 \text { normotensive } \\
\text { women } \\
8 \text { Weeks }\end{array}$ & $\begin{array}{l}\text { IHG3 } \\
94 \pm 6 \\
\text { IHG5 } \\
97 \pm 11\end{array}$ & $\begin{array}{l}\text { IHG3 } \\
88 \pm 5 \\
\text { IHG5 } \\
91 \pm 9\end{array}$ & $\begin{array}{l}\text { IHG3 } \\
57 \pm 7 \\
\text { IHG5 } \\
57 \pm 7\end{array}$ & $\begin{array}{l}\text { IHG3 } \\
54 \pm 6 \\
\text { IHG5 } \\
57 \pm 5\end{array}$ & $\begin{array}{l}\text { SBP } \\
\text { IHG3 }-06.00 \\
\text { IHG5 }-06.00 \\
\text { DBP } \\
\text { IHG3 }-03.00 \\
\text { IHG5 } 00.00\end{array}$ \\
\hline $\begin{array}{l}\text { Badrov et } \\
\text { al., 2013b }\end{array}$ & $\begin{array}{l}\text { Experimental Study } \\
24 \text { hypertensives } \\
10 \text { Weeks }\end{array}$ & $\begin{array}{l}129 \pm \\
16\end{array}$ & $121 \pm 16$ & $72 \pm 9$ & $67 \pm 8$ & $\begin{array}{l}\text { SBP }-08.00 \\
\text { DBP }-05.00\end{array}$ \\
\hline $\begin{array}{l}\text { Baross et } \\
\text { al., } 2013\end{array}$ & $\begin{array}{l}\text { Experimental Study } \\
20 \text { older men } \\
8 \text { Weeks }\end{array}$ & $\begin{array}{l}139 \pm \\
6\end{array}$ & 128 & $85 \pm 7$ & 83 & $\begin{array}{l}\text { SBP - } 11.00 \\
\text { DBP }-02.00\end{array}$ \\
\hline
\end{tabular}

\section{Discussion}

The primary objective of present review was to see isometric training of at least 4 weeks duration on blood pressure in Indian adults. The results suggest that there was mean reduction of $6.72 \mathrm{mmHg}$ in $\mathrm{SBP}$ and $5.28 \mathrm{mmHg}$ in DBP. Even though we did not use any statistical tests, the results also suggest reduction in blood pressure is duration of exercise dependent especially in SBP. Results are comparable to each other since the intensity exercise is same in all three articles (30\% MVC).

Use of isometric exercise as a training modality to reduce blood pressure is relatively new phenomenon even in western population. Majority of publications are published after 2008 and reported a significantly higher reduction in BP than other type of training (i.e) aerobics, physical activity or dynamic resistance exercise. In a recent meta-analysis of 9 articles, Carlson et al., 2014 reported MD of $-6.77 \mathrm{mmHg}$ in SBP and $-3.96 \mathrm{mmHg}$ in DBP. Present review finding is similar for SBP and slightly higher for DBP. However, recent review on meta-analytical studies (total 3) Kulandaivelan et al., 2016 found MD of $-10.13 \mathrm{mmHg}$ in SBP and $-5.84 \mathrm{mmHg}$ in DBP after isometric exercise training. Based on this our present review is slightly higher for SBP and similar for DBP.

Significant of this review is mean reduction of $6.0 \mathrm{mmHg}$ in SBP could reduce mortality from coronary heart disease (CHD) by $12 \%$, stroke by $18 \%$ (Stamler et al., 1989). Another study found that rise of SBP by $6.0 \mathrm{mmHg}$ and DBP by $4.6 \mathrm{mmHg}$ would result in estimated $24 \%$ increased risk for CHD and $48 \%$ increased risk for stroke (Poirier et al., 2006). These findings suggest that isometric training could be used as a preventive measure in young adults to counter future risk of hypertension. The important point to be noted here is that the volume of isometric exercise (15 minutes) used in these articles are much lesser than that of other type of exercises. Main limitation of this review is only 3 articles included for the review and all are from northern India. Another drawback is only 


\section{Journal of Exercise Science \& Physiotherapy, Vol. 12, No. 2, 2016 ISSN: 0973-2020 (Print) \\ ISSN: 2454-6089 (Online)}

one articles is from quality journal. We suggest that future studies should be conducted from other parts of India and the authors should publish in quality journals. All articles used same intensity of exercise for same duration. Future studies should focus to alter the determinants of exercise (i.e) intensity, volume and duration etc.

\section{Conclusion}

The present review conclude that isometric exercise training reduce the blood pressure in Indians that is similar to the findings of western population. So, health care practitioners should prescribe isometric exercise to young adults who are at risk of hypertension.

\section{References}

Anchala, R., Kannuri, N. K., Pant, H., Khan, H., Franco, O. H., Di Angelantonio, E., Prabhakaran, D. 2014. Hypertension in India: a systematic review and metaanalysis of prevalence, awareness, and control of hypertension. Journal of Hypertension, 32(6):1170-77.

Badrov, M. B., Bartol, C. L., DiBartolomeo, M. A., Millar, P. J., McNevin, N. H., McGowan, C. L. 2013a. Effects of isometric handgrip training dose on resting blood pressure and resistance vessel endothelial function in normotensive women. Eur J Appl Physiol, 113(8):2091-100.

Badrov, M. B., Horton, S., Millar, P. J., McGowan, C. L. 2013b. Cardiovascular stress reactivity tasks successfully predict the hypotensive response of isometric handgrip training in hypertensives. Psycho physiology, 50(4):407-414.

Baross, A. W., Wiles, J. D., Swaine, I. L. 2012. Effects of the intensity of leg isometric training on the vasculature of trained and untrained limbs and resting blood pressure in middle aged men. International Journal of Vascular Medicine, ID 964697,8 pages.

Baross, A. W., Wiles, J. D., Swaine, I. L. 2013. Double-leg isometric exercise training in older men. Open Access J Sports Med, 4:33-40.

Carlson, D. J., Dieberg,G., Hess, N. C., Millar, P. J., Smart, N. A. 2014. Isometric Exercise Training for Blood Pressure Management: A Systematic Review and Meta-analysis. Mayo Clin Proc, 89(3):327-34.

Cornelissen, V. A., Smart, N. A. 2013. Exercise training for blood pressure: A systematic review and meta-analysis. $J$ Am Heart Assoc, 2:e004473. DOI: 10.1161/JAHA.112.004473.

Devereux, G. R., Wiles, J. D., Swaine, I. 2011. Markers of isometric training intensity and reductions in resting blood pressure. J Sports Sci, 29(7):715-724.

Gandhi, S. 2016. Effect of isometric hand grip exercise training on cardiovascular and echocardiographic parameters among healthy young males. J Evid Based Med Healthc, 3(1):24-29.

Garg, R., Malhotra, V., Kumar, A., Dhar, U., Tripathi, Y. 2014. Effect of Isometric Handgrip Exercise Training on Resting Blood Pressure in Normal Healthy Adults. Journal of Clinical and Diagnostic Research, 8(9):BC08-BC10.

Howden, R., Lightfoot, J. T., Brown, S. J., Swaine, I. L. 2002. The effects of isometric exercise training on resting blood pressure and orthostatic tolerance in humans. Exp Physiol, 87(4): 507-515.

Kelley, G.A., Kelley, K.S. 2010. Isometric handgrip exercise and resting blood pressure: A meta-analysis of randomized controlled trials. Journal of Hypertension, 28(3):411-18.

Kulandaivelan, S., Verma, S. K., Punia, S. 2016. Effect of Exercise or Physical Activity on Blood Pressure in Hypertension: Evidence from Meta-analytical Studies. Presented and Published in Conference Proceedings of 'One day National 
Conference on Recent Trends in Health Care' on $14^{\text {th }}$ March, 2016 at GJUST, Hisar. [Abstract No: 08; Page No: 04].

Laxmaiah, A., Meshram, I. I., Arlappa, N., Balakrishna, N., Rao, K. M., Reddy, Ch. G., Ravindranath, M., Kumar, S., Kumar, H., Brahmam, G. N. 2015. Socioeconomic \& demographic determinants of hypertension \& knowledge, practices \& risk behaviour of tribals in India.Indian J Med Res, 141(5):697708.

Lim, S. S., Vos, T., Flaxman, A. D., Danaei, G., Shibuya, K., Adair-Rohani, H., Amann, M., Anderson, H. R., Andrews, K. G., Aryee, M., Atkinson, C., Bacchus, L. J., Bahalim, A. N., Balakrishnan, K., Balmes, J., Barker-Collo, S., Baxter, A., Bell, M. L., Blore, J. D., Blyth, F., Bonner, C., Borges, G., Bourne, R., Boussinesq, M., Brauer, M., Brooks, P., Bruce, N. G., Brunekreef, B., BryanHancock, C., Bucello, C., Buchbinder, R., Bull, F., Burnett, R. T., Byers, T. E., Calabria, B., Carapetis, J., Carnahan, E., Chafe, Z., Charlson, F., Chen, H., Chen, J. S., Cheng, A. T., Child, J. C., Cohen, A., Colson, K. E., Cowie, B. C., Darby, S., Darling, S., Davis, A., Degenhardt, L., Dentener, F., Des Jarlais, D. C., Devries, K., Dherani, M., Ding, E. L., Dorsey, E. R., Driscoll, T., Edmond, K., Ali, S. E., Engell, R. E., Erwin, P. J., Fahimi, S., Falder, G., Farzadfar, F., Ferrari, A., Finucane, M. M., Flaxman, S., Fowkes, F. G., Freedman, G., Freeman, M. K., Gakidou, E., Ghosh, S., Giovannucci, E., Gmel, G., Graham, K., Grainger, R., Grant, B., Gunnell, D., Gutierrez, H. R., Hall, W., Hoek, H. W., Hogan, A., Hosgood, H. D. 3rd., Hoy, D., Hu, H., Hubbell, B. J., Hutchings, S. J., Ibeanusi, S. E., Jacklyn, G. L., Jasrasaria, R., Jonas, J. B., Kan, H., Kanis, J. A., Kassebaum, N., Kawakami, N., Khang, Y. H., Khatibzadeh, S., Khoo, J. P., Kok, C., Laden, F., Lalloo, R., Lan, Q., Lathlean, T., Leasher, J. L., Leigh, J., Li, Y., Lin, J. K., Lipshultz, S. E., London, S., Lozano, R., Lu, Y., Mak, J., Malekzadeh, R., Mallinger, L., Marcenes, W., March, L., Marks, R., Martin, R., McGale, P., McGrath, J., Mehta, S., Mensah, G. A., Merriman, T. R., Micha, R., Michaud, C., Mishra, V., Mohd Hanafiah, K., Mokdad, A. A., Morawska, L., Mozaffarian, D., Murphy, T., Naghavi, M., Neal, B., Nelson, P. K., Nolla, J. M., Norman, R., Olives, C., Omer, S. B., Orchard, J., Osborne, R., Ostro, B., Page, A., Pandey, K. D., Parry, C. D., Passmore, E., Patra, J., Pearce, N., Pelizzari, P. M., Petzold, M., Phillips, M. R., Pope, D., Pope, C. A. 3rd., Powles, J., Rao, M., Razavi, H., Rehfuess, E. A., Rehm, J. T., Ritz, B., Rivara, F. P., Roberts, T., Robinson, C., Rodriguez-Portales, J. A., Romieu, I., Room, R., Rosenfeld, L. C., Roy, A., Rushton, L., Salomon, J. A., Sampson, U., Sanchez-Riera, L., Sanman, E., Sapkota, A., Seedat, S., Shi, P., Shield, K., Shivakoti, R., Singh, G. M., Sleet, D. A., Smith, E., Smith, K. R., Stapelberg, N. J., Steenland, K., Stöckl, H., Stovner, L. J., Straif, K., Straney, L., Thurston, G. D., Tran, J. H., Van Dingenen, R., van Donkelaar, A., Veerman, J. L., Vijayakumar, L., Weintraub, R., Weissman, M. M., White, R. A., Whiteford, H., Wiersma, S. T., Wilkinson, J. D., Williams, H. C., Williams, W., Wilson, N., Woolf, A. D., Yip, P., Zielinski, J. M., Lopez, A. D., Murray, C. J., Ezzati, M., AlMazroa, M. A., Memish, Z. A. 2012. A comparative risk assessment of burden of disease and injury attributable to 67 risk factors and risk factor clusters in 21 regions, 1990-2010: a systematic analysis for the Global Burden of Disease Study 2010. Lancet, 380(9859):2224-60.

McGowan, C. L., Levy, A. S., McCartney, N., MacDonald, M. J. 2007a. Isometric handgrip training does not improve flow-mediated dilation in subjects with normal blood pressure. Clinical Science, 112(7-8):403-409.

McGowan, C. L., Visocchi, A., Faulkner, M., Verduyn, R., Rakobowchuk, M., Levy, A. S., McCartney, N., MacDonald, M. J. 2007b. Isometric handgrip training 


\section{Journal of Exercise Science \& Physiotherapy, Vol. 12, No. 2, 2016}

ISSN: 0973-2020 (Print) ISSN: 2454-6089 (Online)

improves local flow-mediated dilation in medicated hypertensives. Eur J Appl Physiol, 99:227-234.

Millar, P. J., Bray, S. R., MacDonald, M. J., McCartney, N. 2008. The hypotensive effects of isometric handgrip training using an inexpensive spring handgrip training device. J Cardiopulm Rehabil Prev, 28(3):203-207.

Millar, P. J., Levy, A. S., McGowan, C. L., McCartney, N., MacDonald, M. J. 2013. Isometric handgrip training lowers blood pressure and increases heart rate complexity in medicated hypertensive patients. Scand J Med Sci Sports, 23(5):620-26.

Owen, A., Wiles, J., Swaine, I. 2010. Effect of isometric exercise on resting blood pressure: A meta-analysis. Journal of Human Hypertension, 24:796-800.

Poirier, P., Giles, T. D., Bray, G. A., Hong, Y., Stern, J. S., Pi-Sunyer, F. X., Eckel, R. H. 2006. Obesity and cardiovascular disease: pathophysiology, evaluation, and effect of weight loss: An update of the 1997 American Heart Association Scientific Statement on Obesity and Heart Disease from the Obesity Committee of the Council on Nutrition, Physical Activity, and Metabolism. Circulation, 113, 898-918.

Ray, C. A., Carrasco, D. I. 2000. Isometric handgrip training reduces arterial pressure at rest without changes in sympathetic nerve activity. Am J Physiol Heart Circ Physiol 279: H245-H249.

Sandhu, J. S., Gill, H. S., Gupta, V., Gurmanpreet. 2014. Effect of Isometric Handgrip Training on Heart rate and Arterial Pressure in Normotensive Individuals. Scholars Journal of Applied Medical Sciences, 2(6A):2010-15.

Stamler, J., Rose, G., Stamler, R., Elliott, P., Dyer, A. \& Marmot, M. 1989. INTERSALT study findings. Public health and medical care implications. Hypertension, 14(5), 570-7.

Stiller-Moldovan, C., Kenno, K., McGowan, C. L. 2012. Effects of isometric handgrip training on blood pressure (resting and $24 \mathrm{~h}$ ambulatory) and heart rate variability in medicated hypertensive patients. Blood Press Monit, 17(2):55-61.

Vandana, Y., Kulandaivelan, S., Verma, S. K., Yadav, R., Sharma, S. 2016. Role of Life Style Modification on Blood Pressure: Evidence from Meta-analytical Studies. Presented and Published in Conference Proceedings of 'One day National Conference on Recent Trends in Health Care' on $14^{\text {th }}$ March, 2016 at GJUST, Hisar. [Abstract No: 21; Page No: 11].

Wiles, J. D., Coleman, D. A., Swaine, I. L. 2010. The effects of performing isometric training at two exercise intensities in healthy young males. Eur J Appl Physiol, 108(3):419-428.

Conflict of Interest: None Declared 


\title{
Effects of Mobilization with Movement (MWM) in Shoulder Impingement Syndrome Patients on Acromiohumeral Distance using Ultrasonography
}

\author{
Dabholkar Ajit and Shetty Shika
}

\begin{abstract}
Aim: To study the effect of MWM on acromiohumeral distance, pain and disability in patients with Shoulder Impingement Syndrome. Method: Fifteen subjects with shoulder impingement syndrome were selected. Participants were treated with MWM posterolateral glide for shoulder for 6 sessions. The main outcome measures include dultrasonographic measurement of the acromiohumeral distance, VAS, SPADI and DASH scale. Results: There were extremely significant changes seen in the acromiohumeral distance in patients with impingement pre and post MWM treatment with $\mathrm{p}$ value of $<0.0001$. Pain and disability also showed extremely significant changes with a $\mathrm{p}$ value of $<0.0001$. Conclusion: The study concludes that MWM is effective in increasing the acromiohumeral distance and in reducing pain and disability in patients with shoulder impingement syndrome.
\end{abstract}

Dabholkar Ajit, Professor and Head of Sports PT,D.Y.PatilSchool of Physiotherapy,Nerul, Navi Mumbai, India. Email:ajitdabholkar78@yahoo.co.in

Shetty Shika,M.P.T Student, D.Y.Patil School of Physiotherapy, Nerul, Navi Mumbai, India.

Email:shika_shetty@hotmail.com
Key Words: Mulligan, Posterolateral glide, SPADI, DASH, Pain, Disability

DOI: $10.18376 / j e s p / 2016 / v 12 / \mathrm{i} 2 / 111262$

\section{Introduction}

Shoulder disorders are among the most common of all peripheral joint complaints (Chard et al,1991; Lo et al,1990). Shoulder Impingement Syndrome (SIS) is defined as the mechanical entrapment of the rotator cuff (mainly the supraspinatus tendon) or the subacromial bursa in the subacromial space between the humeral head and the acromion or coracohumeral ligament (Ellenbecker. et al,2010; Cools et al,2008).It is characterized by shoulder pain that is exacerbated by arm elevation or overhead activities(Ludewig et al,2000; Lukasiewicz et al,1999). The etiology of SIS is multifactorial. Two main contributing factors are: (1) Narrowing of the subacromial space (2) Enlargement of the subacromial tissues (bursae /tendons)(Cholewinski et al,2008; Wang et al,2005).The subacromial space was quantified by the acromiohumeral distance (Cholewinski et al,2008).The subacromial space or acromiohumeral distance could be measured using ultrasound which was found to be a technique that is non-invasive, radiation free and has high validity when compared with others (Azzoni et al,2004).More extensively studied is the subacromial space at the anterior outlet via the acromiohumeral distance measure on ultrasound images with the majority of studies reporting a smaller AHD in those with subacromial impingement syndrome (Bhatt et al,2013). Many factors have been proposed as contributors to the development of shoulder impingement syndrome (Michener et al, 2003).Mechanisms include intrinsic changes in the supraspinatus tendon and extrinsically 


\section{Journal of Exercise Science \& Physiotherapy, Vol. 12, No. 2, 2016 ISSN: 0973-2020 (Print) \\ ISSN: 2454-6089 (Online)}

the direct mechanical compression of the supraspinatus tendon in the subacromial space (Neer ,1983). Characterizing supraspinatus tendon dimension and the tendon thickness in proportion to the subacromial space will aid our understanding of the mechanism of this (Michener. et al,2015).Ultrasonography is a useful technique for imaging a large variety of musculoskeletal disorders(Bhatt et al,2013).Studies suggest that shoulder ultrasound performed in patients with Shoulder Impingement Syndrome visually showed decreased size of subacromial space and rotator cuff thickness (When compared to persons not affected by this condition) (Cholewinski et al,2008).Conservative treatment of the shoulder impingement syndrome consists of a wide range of procedures, manual therapy being one of them (Olivera et al, 2012).MWM is a manual therapy technique in which a manual force, usually in the form of a joint glide is applied to a motion segment and sustained while a previously impaired action (e.g.painful abduction movement) is performed (Vicenzino et al,2007). If the active movement performed is pain free, the orientation of the glide will be considered adequate (Mulligan et al,2014). The principles for this type of joint mobilization are based on analyzing and correcting any minor positional fault in the patient, which according to the MWM theory occurs due to the various soft and/or bony tissue lesions in/around the joint (Mulligan et al,2014).The purpose of this study was to investigate the effects of MWM on AHD, pain and disability in patients with Shoulder Impingement Syndrome.

\section{Methods}

It's a Quasi experimental type of study. All the fifteen $(n=15)$ subjects were selected from the Physiotherapy OPD at Dr.D.Y.Patil Hospital and Research Center, Navi Mumbai. The study duration was 1 year. Patients diagnosed with Shoulder Impingement Syndrome were selected. Inclusion criteria: Subjects selected for the study were included on the basis of those showing Positive Hawkins Kennedy test, Positive Neer's Impingement test and Positive Horizontal Adduction test. Exclusion criteria: Those having complete rotator cuff tear, H/O active shoulder dislocation/subluxation or fracture, H/O Shoulder surgery and Adhesive capsulitis. Materials used were Ultrasound Machine (Mindray) with 7$\mathrm{MHz}$ linear tranducer used for measuring AHD and Supraspinatus tendon thickness, Shoulder Pain and Disability Index (SPADI), Disabilities of Arm, Shoulder and Hand (DASH) and Stool.

\section{Procedure}

Approval for the study was gained from the Institutional Ethics Committee. All subjects were explained the purpose of the study and written consent was taken from all of them prior to assessment. Patients meeting the inclusion criteria were selected for the study. Proforma was filled by interviewing the subjects which included information about their gender, age, height, weight, location and duration of symptoms, previous history of shoulder pain, and pain intensity using $10 \mathrm{~cm}$ Visual Analogue Scale. Pre evaluation was done followed by treatment protocol of MWM for 6 sessions with 24 hours between sessions after which post evaluation was done. Pre and Post Evaluation were done using following outcome measures:

- Functional status of patients were assessed with SPADI and DASH scale (Roach et al,1991; Hudak et al,1996).

- USG measurements of AHD and SST. 


\section{Journal of Exercise Science \& Physiotherapy, Vol. 12, No. 2, 2016 ISSN: 0973-2020 (Print) \\ ISSN: 2454-6089 (Online)}

The intervention included MWM posterolateral glide for shoulder. Patient seated at the edge of a chair. Patients arm should be in external rotation while performing abduction. The therapist stands on the lateral side of the unaffected shoulder. Therapist stabilizes scapula with one hand. Thenar eminence of the other hand is placed medial to the head of humerus. Therapist glides the humeral head in postero-lateral-inferior direction with thenar eminence. Patient performs the offending movement while the glide is sustained. This movement should now become pain-free. Passive overpressure can be given by the patient at the end of new available range using his other hand. The hand of the therapist should also move along with the movement in order to sustain the glide along the treatment plane. Allow upward rotation of the scapula as the patient moves his shoulder (Mulliganet al,2014).

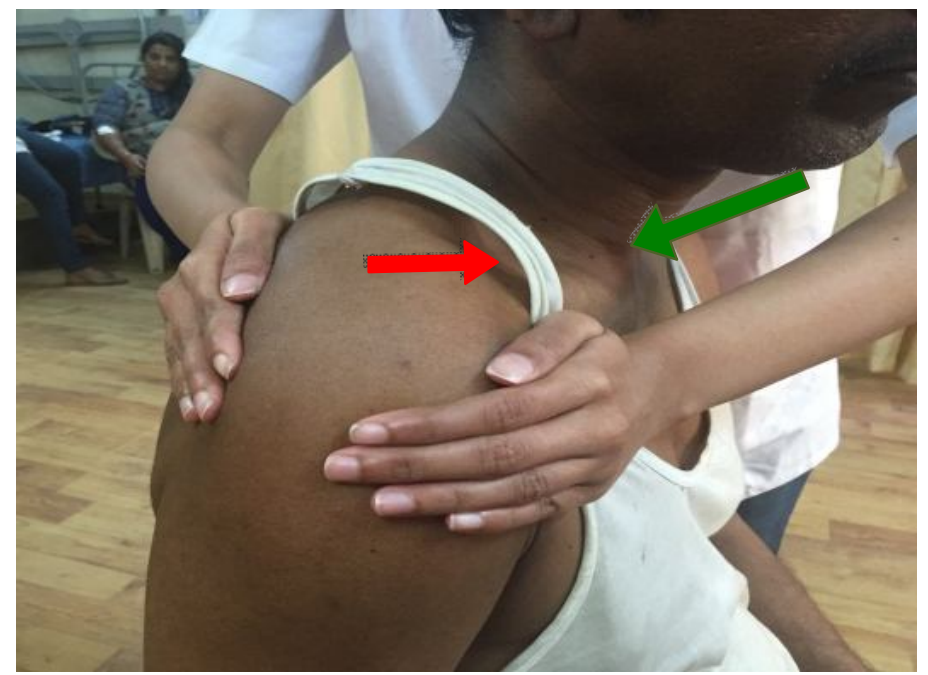

Figure 1. MWM Posterolateral glide for Shoulder

MWM - 10 repetitions daily, $30 \mathrm{sec}$ rest period between sets, 6 sessions with 24 hours between sessions.USG measurements of each participant, AHD and SST were scanned using a Mindray ultrasound machine in conjunction with a 7-MHz linear transducer.

\section{AHD: Acromio-humeral distance}

The AHD measurement was taken with the participant in sitting position. His/her head was in neutral position, arm in $0^{\circ}$ flexion, elbow were in full extension and forearm in neutral position. The transducer was placed on the lateral surface of the shoulder along the longitudinal view and was measured from the infero-lateral edge of acromion to the apex of the greater tubercle (Cholewinski et al,2008). 
Journal of Exercise Science \& Physiotherapy, Vol. 12, No. 2, 2016

ISSN: 0973-2020 (Print)

ISSN: 2454-6089 (Online)

Figure 2. Acromiohumeral distance SST: Supraspinatus tendon thickness

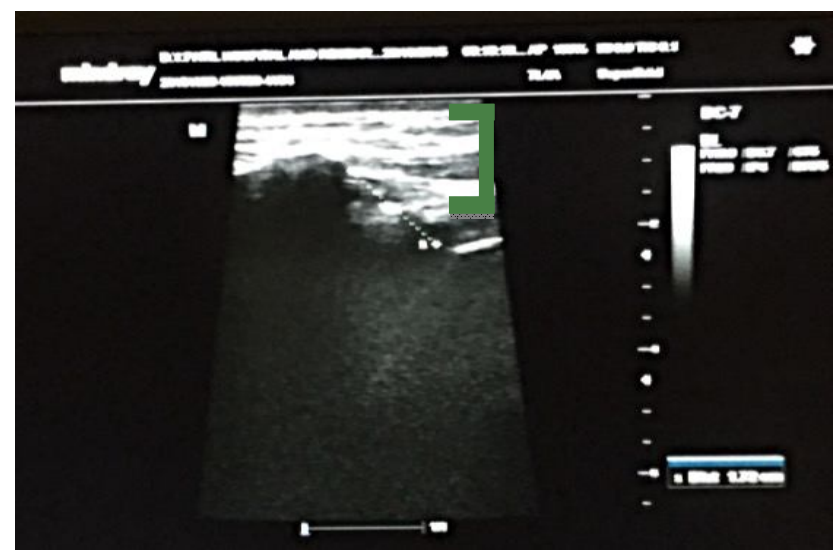

SST was taken with the patient in sitting position. His/her head was in neutral position, with the palmar side of the hand on the superior aspect of the iliac crest, with elbow flexed and directed posteriorly towards the midline. The SST was scanned in transverse view and the thickness of the tendon was measured at $30 \mathrm{~mm}$ lateral to the long head of biceps tendon (Cholewinski et al,2008; Wallny et al,1999).

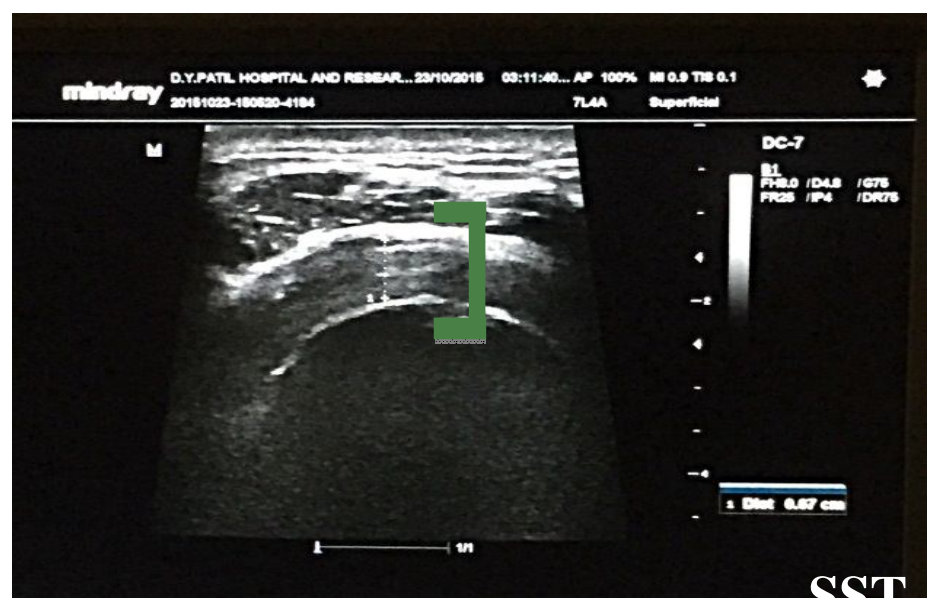

Figure 3. Supraspinatus thickness

The data was statistically analyzed by Wilcoxon Test. 


\section{Results}

All subjects completed the intervention program study. The demographic variables of the subjects were as follows:

Table 1. Demographic Variables

\begin{tabular}{lcc}
\hline Variables & Mean & Standard Deviation \\
\hline Age & 53.86 & 8.84 \\
Duration of pain & 2.86 & 1.99 \\
VAS & 6.52 & 1.45 \\
M:F & $7: 8$ & \\
\hline
\end{tabular}

Table 2. Demographic Data

\begin{tabular}{|c|c|c|c|c|}
\hline \multirow[t]{2}{*}{ VARIABLES } & \multicolumn{2}{|c|}{ Mean+/-SD } & \multirow[t]{2}{*}{$P$ value } & \multirow[t]{2}{*}{ Significance } \\
\hline & Pre & Post & & \\
\hline AHD & $\begin{array}{l}0.92+/- \\
0.16\end{array}$ & $\begin{array}{l}1.25+/- \\
0.16\end{array}$ & $<0.0001 * * *$ & $\mathrm{ES}$ \\
\hline SST & $\begin{array}{l}0.61+/- \\
0.08\end{array}$ & $\begin{array}{l}0.68+/- \\
0.07\end{array}$ & $<0.0039 * *$ & VS \\
\hline SPADI Scale & $\begin{array}{l}46.96+/- \\
9.64\end{array}$ & $\begin{array}{l}9.73+/- \\
3.34\end{array}$ & $<0.0001 * * *$ & $\mathrm{ES}$ \\
\hline DASH Scale & $\begin{array}{l}51.71+/- \\
7.84\end{array}$ & $\begin{array}{l}28.63+/- \\
7.20\end{array}$ & $<0.0001 * * *$ & $\mathrm{ES}$ \\
\hline $\begin{array}{l}\text { VAS-Hawkins Kennedy } \\
\text { Test }\end{array}$ & $\begin{array}{l}6.72+/- \\
1.53\end{array}$ & $\begin{array}{l}0.48+/- \\
0.43\end{array}$ & $<0.0001 * * *$ & ES \\
\hline VAS-Neers & $\begin{array}{l}6.75+/- \\
1.55\end{array}$ & $0.38+/-$ & $<0.0001 * * *$ & $\mathrm{ES}$ \\
\hline Impingement Test & 1.55 & 0.37 & & \\
\hline $\begin{array}{l}\text { VAS-Horizontal } \\
\text { Adduction Test }\end{array}$ & $\begin{array}{l}6.06+/- \\
1.73\end{array}$ & $\begin{array}{l}0.32+/- \\
0.38\end{array}$ & $<0.0001 * * *$ & $\mathrm{ES}$ \\
\hline $\begin{array}{l}\text { Internal Rotation } \\
\text { Strength }\end{array}$ & $\begin{array}{l}2.40+/- \\
1.12\end{array}$ & $\begin{array}{l}3.33+/- \\
1.23\end{array}$ & $<0.0674$ & NS \\
\hline $\begin{array}{l}\text { External Rotation } \\
\text { Strength }\end{array}$ & $\begin{array}{l}0.93+/- \\
1.03\end{array}$ & $\begin{array}{l}2.53+/- \\
0.91\end{array}$ & $\begin{array}{c}< \\
0.0010^{* * *}\end{array}$ & $\mathrm{ES}$ \\
\hline
\end{tabular}

\section{Discussion}

In a study by Hio-Teng Leong et al 2012, the subacromial space was quantified by the AHD. The etiology of SIS is multifactorial, one of them being narrowing of subacromial space (Cholewinski et al,2008; Wang et al,2005). A study by Jerzy et al, 2008 suggested that shoulder ultrasound performed in patients with symptoms of SIS usually showed decreased size of subacromial space. Ultrasonographic assessment of humeral head elevation, measured as the AGT distance (the distance between the infero-lateral edge of acromion and the apex of the greater tuberosity of humerus), proved to be useful in establishing the diagnosis of the subacromial impingement syndrome of the 


\section{Journal of Exercise Science \& Physiotherapy, Vol. 12, No. 2, 2016 ISSN: 0973-2020 (Print) \\ ISSN: 2454-6089 (Online)}

shoulder(Neer,1983). Our study concludes that Mulligan MWM posterolateral glide helps in correcting positional fault by repositioning the joint causing it to track normally, (Hing,2007) thus increasing AHD post Mulligan treatment session. An extrinsic mechanism is theoretically supported which states direct mechanical compression; measures of direct tendon compression during arm elevation are needed to verify this mechanism. Surgical intervention to increase subacromial space may be considered if tendon compression can be verified (Lori et al,2015). Statistically significant difference in rotator cuff thickness between the affected and unaffected joints found within the study group results from the decrease in thickness of the rotator cuff during the development of SIS, which was observed by some authors (Seibold et al,1999; Wiener et al,1993).Our study concludes that the supraspinatus tendon compression is relieved because of increase in the AHD pre to post Mulligan MWM posterolateral glide treatment ,because of which there is slight increase in the supraspinatus tendon thickness. A study done by Aimie et al,2008 have shown that MWM with supervised exercise showed the highest percentage of change in decreasing pain and improving functions from pre to post treatment. Since the SPADI function test is based on shoulder pain with functional activities thus, interventions resulting in pain reduction would also result in an improved SPADI score. One of the case report done by Lucy et al, 2006 concludes that MWM may be an effective treatment intervention for patients with impingement which has an improvement in SPADI scores, which is proved in our study. The Disabilities of the Arm, Shoulder, and Hand questionnaire (DASH), is the most widespread and best-tested and characterized instrument for shoulder assessment (Angst et al,2011).Also, we have found that MWM helps in decreasing pain and improving functions from pre to post Mulligan MWM posterolateral glide treatment, therefore improving DASH scores. A study done by Aimie et al, suggested that the MWM group had a higher percentage of change from pre to post treatment on all three pain measures (VAS, Neer, Hawkins Kennedy) (Aimieet al,2008).It is likely that the movement produced by MWM techniques resulted in pain reduction through activation of mechanoreceptors inhibiting nociceptive stimuli through the gate control mechanism or through facilitation of synovial fluid nutrition (Melzack et al,1965; Wall 1978; Threlkeld1992).MWM also has an hypoalgesic and sympathetic nervous system (SNS) excitation effect (Wallny et al,1999). Therefore in our study we found that because of pain reduction the VAS scales have improved post Mulligan MWM posterolateral glide treatment improving patients functions.

\section{Conclusion}

Thus are study concludes that MWM is effective in increasing the acromiohumeral distance in patients with shoulder impingement syndromeand it is also effective in reducing pain and disability thereby improving the patients functions.

\section{Acknowledgements}

Sincere thanks to all the participants of the study and the HOD of the Radiology dept Dr. Madan Manmohan and Senior Resident Dr.Shipra Singh.

\section{References}

Aimie F. Kachingwe, EdD, Beth Phillips, et al.(2008). Comparison of Manual TherapyTechniques with Therapeutic Exercise in the Treatment of Shoulder Impingement: A Randomized Controlled Pilot Clinical Trial.J Man ManipTher.16(4):238-247. 


\section{Journal of Exercise Science \& Physiotherapy, Vol. 12, No. 2, 2016}

ISSN: 0973-2020 (Print)

ISSN: 2454-6089 (Online)

Angst.F, Schwyzer.HK, Aeschlimann.A,et al.(2011).Measures of Adult ShoulderFunction.Arthritis Care \& Research.174-188.

Azzoni R, Cabiza P, Parrini M.(2004). Sonographic evaluation of subacromial space.Ultrasonics.42:683-687.

Bhatt .S, Bhargav S.K.(2013).Dynamic musculoskeletal sonography.

JIMSA.26(1):21-24

Chard MD, Hazleman BL, King RH, Reiss BB.(1991). Shoulder disorders in the elderly: a community survey. Arthritis Rheum. 34:766-769.

Cholewinski JJ, Kusz DJ, Wojciechowski P, et al.(2008). Ultrasound measurement of rotator cuff thickness and acromio-humeral distance in the diagnosis of subacromial impingement syndrome of the shoulder.Knee Surg Sports Traumatol Arthrosc. 16:408-414.

Cools AM, Cambier D, Witvrouw EE. (2008).Screening the athlete's shoulder for impingement symptoms: a clinical reasoning algorithm for early detection of shoulder pathology. Br J Sports Med. 42:628-635.

DeSantis.L; Hasson.S et al.(2006).Use of Mobilization with Movement in the Treatment of a Patient with Subacromial Impingement: A Case Report.J Man ManipTher .77-87.

Ellenbecker TS, Cools A.(2010).Rehabilitation of shoulder impingement syndrome and rotator cuff injuries: an evidence-based review. $\mathrm{Br} \quad \mathrm{J}$ SportsMed. 44:319-327.

Hing.W.(2008).Mulligan's mobilisation with movement: a review of the tenets and prescription of MWMs.

NewZealand Journal of Physiotherapy.36(3):144-164

Hudak P, Amadio PC, Bombardier C, and the Upper Extremity Collaborative Group.(1996). Development of an Upper Extremity Outcome Measures: The DASH(Disabilities of the Arm, Shoulder, and Hand). American Journal of Industrial Medicine .29:602-608.

Leong HT, Tsui S, Ying M et al .(2012) .Ultrasound measurements on acromiohumeral distance and supraspinatus tendon thickness: test-retest reliability and correlations with shoulder rotational strengths. J Sci Med Sport .15:284-291.

Lo YP, Hsu YCS, Chan KM.(1990). Epidemiology of shoulder impingement in upper arm sports events. Br J Sports Med. 24:173-177.

Ludewig PM, Cook TM.(2000). Alterations in shoulder kinematics and associated muscle activity in people with symptoms of shoulder impingement. PhysTher.80:276-91.

Lukasiewicz AC, McClure P, Michener L, Pratt N, Sennett B. (1999).Comparison of 3-dimensional scapular position and orientation between subjects with and without shoulder impingement. J Orthop Sports PhysTher.29:574-83.

Melzack R, Wall PD.(1965). Pain mechanisms: A new theory. Science.150:971979.

Michener LA, McClure PW, KardunaAR. (2003).Anatomical and biomechanical mechanisms of subacromial impingement syndrome. Clin Biomech. 18:369-379.

Michener.L ,Sevgi S, Yesilyaprak.S et al.(2015). Supraspinatus tendon and subacromial space parameters measured on ultrasonographic imaging in 
subacromial impingement syndrome. Knee Surg Sports Traumatol Arthrosc.363-369.

Mulligan .B , Kumar .D. (2014).Manual of Mulligan Concept,Capri Institute of Manual Therapy, Chapter 8 ,Shoulder Joint,Page no 148.

NeerCS .(1983). Impingement lesions. Clin Orthop Relat Res. 3(173):70-77.

Olivera C. Djordjevic, MD, Vukicevic.D, MD, Katunac.L,et al.(2012) .Mobilization with movement and kinesiotaping compared with a supervised exercise program for painful shoulder: results of a clinical trial. Journal of Manipulative And Physiological Therapeutics.35(6):45463

Roach KE, Budiman-Mak E, Songsiridej N, Lertratanakul Y.(1991) Development of a shoulder pain and disability index. Arthritis Care Res.4(4):143-9.

Seibold CJ, Mallisee TA, Erickson SJ, Boynton MD, Raasch WG, Timins ME (1999) Rotator Cuff: Evaluation with US and MR Imaging. Radiographics .19:685-705.8.

Threlkeld AJ. (1992).The effects of manual therapy on connective tissue. Phys Ther.72: 893-902.

Vicenzino.B, Paungmali.A and Teys.P.(2007). Mulligan's mobilization-withmovement, positional faults and pain relief: Current concepts from a critical review of literature.Manual Therapy.12 (2): 98-108.

Wall PD.(1978). The gate control theory of pain mechanisms: An reexamination and a re-statement. Brain.101:1-18.

Wallny T, Wagner UA, Prange S, et al.(1999). Evaluation of chronic tears of the rotator cuff by ultrasound.J Bone Joint Surg .81:675-678.

Wang HK, Lin JJ, Pan SL, et al.(2005).Sonographic evaluations in elite college baseball athletes.Scand J Med Sci Sports. 15:29-35.

Wiener SN, Seitz WH Jr.(1993).Sonography of the shoulder in patients with tears of the rotator cuff: accuracy and value for selecting surgical options. AJR Am J Roentgenol.160:103-107.

Conflict of Interest: None Declared 


\title{
A Cross Sectional Survey on Prevalence Rate and Physical Therapy Awareness of Cerebral Palsy in Panipat City
}

\author{
Kanika Bhaskar, Shefali Kapoor, Jyoti and Vinay Jagga
}

\begin{abstract}
Aim: This cross-sectional study assessed prevalence rate and physical therapy awareness of cerebral palsy (CP) in Panipat city. Method: A total two hundred (107 male and 93 female) of age between 2 to 7 year subject with premature birth $(<36$ weeks) and low birth weight $(<2500 \mathrm{~g})$ participated in the study. A structured questionnaire which sought information on socio- demographics, gestational age, birth weight, mother history, neonatal history, MAS and DTR scale was used to obtain data from the respondents who were taken from all government and private hospitals/ nursing homes having obstetrics and gynaecology department. Result: More than one fourth of the respondents, 54 (27\%) reported diagnosis was cerebral palsy hence $27.0 \%$ is reported prevalence rate and $42.6 \%$ was aware of physical therapy importance in cerebral palsy. There were significant associations between gestational age and low birth weight. A significant association was also found between delayed cry and birth asphyxia and cerebral palsy. Conclusion: It was concluded from the results of the present study that there was a high prevalence rate of CP and low physical therapy awareness in Panipat city. It was also found that cerebral palsy was significantly influenced by prematurity and low birth weight.
\end{abstract}

Kanika Bhaskar, Shefali Kapoor, Jyoti and Vinay

Jagga

E-mail:kanikabhaskar4@gmail.com

Prem Physiotherapy and Rehabilitation College

Panipat(Haryana) India
Key Words: Physical Therapy, Cerebral Palsy,Gestational, MAS, DTR

DOI: $10.18376 / j e s p / 2016 / v 12 / i 2 / 111263$

\section{Introduction}

Cerebral palsy (CP) describes a group of permanent disorders of the development of movement and posture, causing activity limitation that is attributed to non-progressive disturbances that occurred in the developing fetal or infant brain (Zeljka et al 2011). The motor disorders of cerebral palsy are often accompanied by disturbances of sensation, perception, cognition, communication and behavior by epilepsy, and by secondary musculoskeletal problems (Hwang et al 2011). Cerebral palsy is a static neurologic condition resulting from brain injury that occurs before cerebral development is complete. Because brain development continues during the first two years of life, cerebral palsy can result from brain injury occurring during the prenatal, perinatal, or postnatal periods (Bass 1999). The CP encompasses a spectrum of motor disorders of varying tone, anatomical distribution and severity. According to clinical classification $\mathrm{CP}$ is divided into Spastic, Dyskinetic, Hypotonic/Ataxic and Mixed type of CP. On the other hand CP is divided into Hemiplegia, Diplegia, Quadriplegia, Triplegia, Monoplegia and Double Hemiplegia on the basis of anatomical classification (Nadire 1999). Upper motor neuron 


\section{Journal of Exercise Science \& Physiotherapy, Vol. 12, No. 2, 2016 ISSN: 0973-2020 (Print) \\ ISSN: 2454-6089 (Online)}

syndrome often leads to common patterns of motor dysfunction and characteristic spasticity and contractures (Mayer et al 1997). Selective dorsal rhizotomy is a procedure intended to minimize or eliminate spasticity by selectively cutting dorsal rootlets from spinal cord segments L1 to S2. Postoperatively, it can create proprioceptive loss, bladder or bowel dysfunction, prolonged marked hypotonia, persistent back pain or spinal deformities (McLaughlin etal2002). Adequate knowledge of a disease condition has been reported to influence the patient's attitude and practice in the management of their illness and improving physical therapy awareness is known to improve compliance with treatment in CP. Therefore the present study assessed prevalence rate and physical therapy awareness in Panipat city (Haryana) India.

\section{Materials and methods}

This cross-sectional study recruited two hundred (107 male and 93 female) subject with premature birth and low birth weight. The selected hospitals were all government and private hospitals/ nursing homes having obstetrics and gynaecology department etc. The inclusion criteria for participation in the study involved low birth weight $(<2500 \mathrm{~g})$ and premature birth ( $<36$ weeks) of $2-7$ year of age, Rh incompatibility and birth asphyxia. Subjects were excluded if presented or reported any trauma after birth, genetic abnormality and age less than 2 years. Ethical approval was obtained from the Prem Physical Therapy and Rehabilitation College. Permission to conduct study was obtained from government and private hospitals/ nursing homes of Panipat city which provide us the history of children delivered in the hospital. Each respondent gave informed consent to participate in the study. Parents of subject were contacted and asked for the informed consent and a detailed questionnaire specifying cerebral palsy was filled by the same. We have used MAS and DTR scale as an assessment tool. Reflex hammer used to elicit the DTR. Subject who were not aware of the importance of physical therapy interventions, we were told them the importance for the purpose of awareness and better quality of life of subjects. The questionnaire used in the study was developed by a panel of experts. The questionnaire sought information on socio- demographics, gestational age, birth weight, mother history, neonatal history, MAS and DTR scale. The questionnaire was tested for reliability was determined in a pilot study among 20 subjects with prematurity and low birth weight. Consequently, items on the questionnaire that were ambiguous or extraneous were either modified or expunged. The internal consistency of the questionnaire was found to be 0.89 on Cronbach 's alpha. The answering options were - Yes or No. A correct response was assigned score of 1, incorrect response was given a score of 0. Data were summarized using descriptive statistics of mean, standard deviation, frequency and percentage. Inferential statistics of Chi Square test was used to determine associations among gestational age, birth weight, birth asphyxia, delayed cry, place of delivery, $\mathrm{Rh}$ incompatibility and mother history of disease. 


\section{Result}

The mean age of the respondents in this study was $4.51 \pm 1.70$ years (Table 1 ). The study recruited higher prevalence $27.0 \%$ of $\mathrm{CP}$ with prematurity and low birth weight and low physical therapy awareness $(42.6 \%)$. The $80.0 \%$ had reported delayed cry and $76.1 \%$ had birth asphyxia in influenced respondents. The $38.0 \%$ had CP who had taken birth in government hospitals while $16.0 \%$ have in case of private hospitals.

Table 1. Distribution of children according to age, birth weight and gestational age

\begin{tabular}{lll}
\hline Age & Mean \pm SD & $4.51 \pm 1.70$ \\
& Range & $2-7$ \\
Birth weight $($ Kg) & Mean \pm SD & $1.99 \pm .30$ \\
\multirow{2}{*}{ Gestational age(weeks) } & Range & $<2.5$ \\
& Mean \pm SD & $34.92 \pm 1.49$ \\
\hline
\end{tabular}

Table 2. Distribution of children according to history of disease, infection during pregnancy and accidental history

\begin{tabular}{|c|c|c|c|c|}
\hline & & \multirow{2}{*}{$\begin{array}{c}\text { Normal } \\
\text { Frequency }(\%)\end{array}$} & \multirow{2}{*}{$\begin{array}{l}\text { Cerebral palsy } \\
\text { Frequency }(\%)\end{array}$} & \multirow{2}{*}{$\begin{array}{c}\text { Other } \\
\text { Frequency }(\%)\end{array}$} \\
\hline & & & & \\
\hline During pregnancy any & High BP & $25(54.3 \%)$ & $18(39.1 \%)$ & $3(6.5 \%)$ \\
\hline \multirow[t]{4}{*}{ history of disease } & Low BP & $18(56.2 \%)$ & $14(43.8 \%)$ & $0(0.0 \%)$ \\
\hline & Anaemia & $75(55.1 \%)$ & $51(37.5 \%)$ & $10(7.4 \%)$ \\
\hline & Diabetes & $20(100.0 \%)$ & $0(0.0 \%)$ & $0(0.0 \%)$ \\
\hline & Any other & $14(56.0 \%)$ & $11(44.0 \%)$ & $0(0.0 \%)$ \\
\hline During pregnancy any & Syphilis & $17(40.5 \%)$ & $20(47.6 \%)$ & $5(11.9 \%)$ \\
\hline \multirow[t]{2}{*}{ history of infection } & Torch & $18(58.1 \%)$ & $13(41.9 \%)$ & $0(0.0 \%)$ \\
\hline & Any other & $4(40.0 \%)$ & $4(40.0 \%)$ & $2(20.0 \%)$ \\
\hline $\begin{array}{l}\text { Accidental history } \\
\text { during pregnancy }\end{array}$ & Yes & $6(25.0 \%)$ & $15(62.5 \%)$ & $3(12.5 \%)$ \\
\hline
\end{tabular}

Table 3. Distribution of children with cerebral palsy according to sex, age, birth weight, gestational age, place of delivery, consanguineous marriage, $\mathbf{R h}$ incompatibility, multiple pregnancy, birth asphyxia and delayed cry

\begin{tabular}{|c|c|c|c|c|}
\hline & & Normal & $\begin{array}{c}\text { Cerebral } \\
\text { palsy }\end{array}$ & Other \\
\hline & & $\begin{array}{c}\text { Frequency } \\
(\%)\end{array}$ & $\begin{array}{c}\text { Frequency } \\
(\%)\end{array}$ & $\begin{array}{c}\text { Frequency } \\
(\%)\end{array}$ \\
\hline \multirow{3}{*}{ Sex } & Male & $69(64.5 \%)$ & $30(28.0 \%)$ & $8(7.5 \%)$ \\
\hline & Female & $67(72.0 \%)$ & $24(25.8 \%)$ & $2(2.2 \%)$ \\
\hline & $\leq \mathbf{3}$ & $45(68.2 \%)$ & $19(28.8 \%)$ & $2(3.0 \%)$ \\
\hline \multirow[t]{2}{*}{ Age } & $4-5$ & $45(67.2 \%)$ & $19(28.4 \%)$ & $3(4.5 \%)$ \\
\hline & $\geq 6$ & $46(68.7 \%)$ & $16(23.9 \%)$ & $5(7.5 \%)$ \\
\hline \multirow{2}{*}{ Birth weight } & $\leq 1.86$ & $19(30.2 \%)$ & $39(61.9 \%)$ & $5(7.9 \%)$ \\
\hline & $\geq 1.87$ & $117(85.4 \%)$ & $15(10.9 \%)$ & $5(3.6 \%)$ \\
\hline
\end{tabular}




\begin{tabular}{|c|c|c|c|c|}
\hline \multirow{2}{*}{ Gestational age } & $\leq \mathbf{3 4}$ & $20(29.9 \%)$ & $43(64.2 \%)$ & $4(6.0 \%)$ \\
\hline & $\geq 34$ & $116(87.2 \%)$ & $11(8.3 \%)$ & $6(4.5 \%)$ \\
\hline \multirow[t]{2}{*}{ Place of delivery } & Government & $57(58.2 \%)$ & $38(38.0 \%)$ & $5(5.1 \%)$ \\
\hline & Private & $79(77.5 \%)$ & $16(16.0 \%)$ & $5(4.9 \%)$ \\
\hline $\begin{array}{l}\text { Consanguineous } \\
\text { marriage }\end{array}$ & Yes & $5(27.8 \%)$ & $11(61.1 \%)$ & $2(11.1 \%)$ \\
\hline Rh incompatibility & Yes & $5(16.1 \%)$ & $24(77.4 \%)$ & $2(6.5 \%)$ \\
\hline Multiple pregnancy & Yes & $24(60.0 \%)$ & $14(35.0 \%)$ & $2(5.0 \%)$ \\
\hline Birth asphyxia & Yes & $6(9.0 \%)$ & $51(76.1 \%)$ & $10(14.9 \%)$ \\
\hline Delayed cry & Yes & $4(6.2 \%)$ & $52(80.0 \%)$ & $9(13.8 \%)$ \\
\hline
\end{tabular}

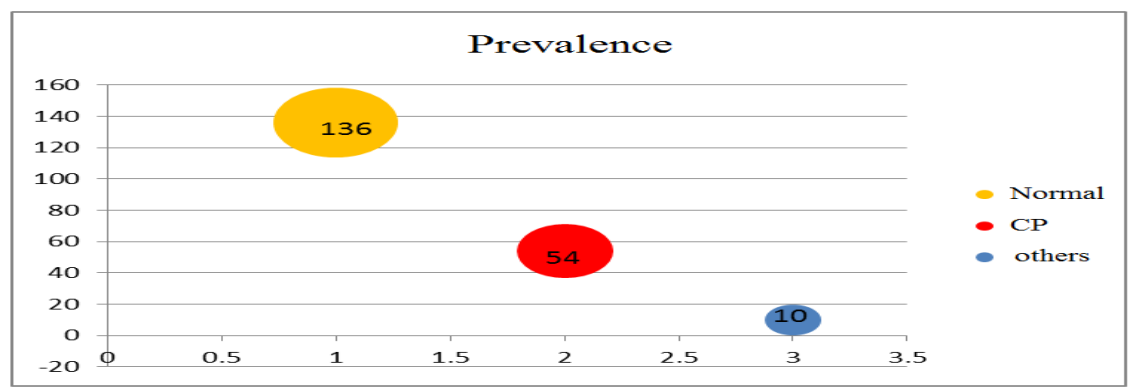

Figure 1. Frequency of Prevalence rate of cerebral palsy

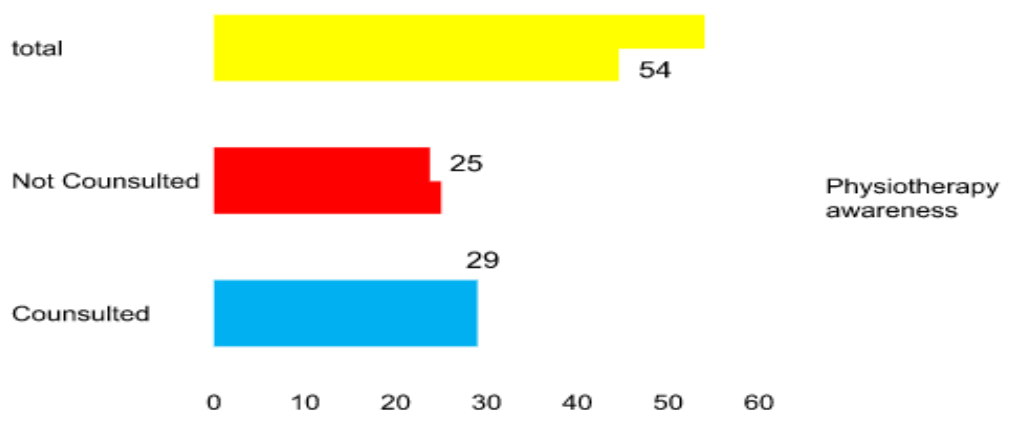

Figure 2. Frequency of physical therapy awareness

Respondents, who had received treatment from physiotherapist, were less than half i.e. $20.3 \%$. Two cases of Autism, two cases of deaf and dumb, three cases of MR, three cases of western syndrome, and seven cases of epilepsy was found in the present study. A majority of respondents (72\%) diagnosis is normal and $23.6 \%$ respondent's diagnosis is $\mathrm{CP}$ in consanguineous marriage group $\left(\mathrm{p}=0.000^{* *}\right)$. There was significant association between consanguineous marriage and $\mathrm{CP}$. A majority of respondents $(77.5 \%)$ diagnosis is normal and $17.8 \%$ respondent's diagnosis is $\mathrm{CP}$ and $4.7 \%$ others in Rh incompatibility group $\left(\mathrm{p}=0.000^{* *}\right)$. There was significant association between Rh incompatibility and CP. A majority of respondents $(80.0 \%)$ diagnosis is $\mathrm{CP}$ and $6.2 \%$ respondent's diagnosis is Normal in Delayed cry group $\left(\mathrm{p}=0.000^{* *}\right)$. A majority of respondents $(76.1 \%)$ 


\section{Journal of Exercise Science \& Physiotherapy, Vol. 12, No. 2, 2016 ISSN: 0973-2020 (Print) \\ ISSN: 2454-6089 (Online)}

diagnosis is $\mathrm{CP}$ and $9 \%$ respondents diagnosis is Normal in Birth asphyxia group is $(\mathrm{p}=$ $\left.0.000^{* *}\right)$. There was significant association between birth asphyxia and CP. A majority of respondents $(44.7 \%)$ diagnosis is $\mathrm{CP}$ in jaundice group. There was significant association between jaundice and $\mathrm{CP}\left(\mathrm{p}=0.000^{* *}\right)$. In Gestational age group $\leq 34$, majority of respondents $(64.2 \%)$ diagnosis is CP. But in case of Gestational age group "> 34 ", majority of respondents $(87.2 \%)$ diagnosis is normal. $(\mathrm{p}=0.000)$. There was significant association between gestational age and CP. In case of birth weight group " $\leq 1.86$ ", majority of respondents (61.9\%) diagnosis is CP. While in case of birth weight group "> 1.86 ", majority of $85.4 \%$ of respondent's diagnosis is normal $(\mathrm{p}=0.000)$. There was significant association between birth weight and CP.

\section{Discussion}

The results of the present study show that there was a high prevalence rate of $\mathrm{CP}$ and low physical therapy awareness in Panipat city. Maryam et al. (2013) reported the prevalence of CP expressed by gestational age was highest in children born before 28 weeks' gestation (111.80 per 1000 live births; 95\% CI 69.53-179.78; p<0.0327). Yudkin and Johnson (1995) investigated the risk of cerebral palsy following intrapartum asphyxia at term, and the contribution of intrapartum asphyxia at term to the overall rate of cerebral palsy and recognized that the initial hypoxial insult might have occurred in the antenatal period. Vandana et al (2014) also supported the results of the present study that a disability is restriction or lack of ability to perform an activity in a manner or within the range considered normal for a human being. The prevalence of disability is 7 per 1000 live births in India. 20\% are not aware about the legal issues for person with disability in developing countries. Kyllerman et al. (1982) reported that hyperbilirubinemia was present as a contributory factor in $32 \%$. Following the development of safe routines for testing and treatment, hyperbilirubinemia has almost disappeared as a risk factor in Sweden. The subgroup of children born preterm, who are more vulnerable to hyperbilirubinemia than those born at term, had decreased from $35 \%$ to $19 \%$ in the present one. There are certain limitations addressed during the present research study like some hospitals did not have their records maintained and others had the records but without any proper documentation i.e. contact number and address of the patients etc. Some hospitals did not maintain maternal screening records properly and proper neonatal examination records were also not present. In 70\%-80\% of cases Apgar scoring was not found in records, which is one of the main markers of CP.

\section{Clinical Implication of findings}

Maternity care must continue to focus on antenatal risk factors so that pregnancies with risk associated with cerebral palsy can be identified and managed appropriately; Efforts must continue to prevent low birth weight and preterm births and where they are inevitable to provide antenatal and neonatal interventions to reduce associated risk factors of CP.Multiple births should continue to be the subject of close surveillance in an effort to reduce the associated mortality and morbidity, particularly cerebral palsy; Due to its association with cerebral palsy, delayed child bearing and the transfer of multiple embryos with fertility treatment must be addressed through education and policy initiatives. Doctor should aware the patient for regular developmental assessment and regular check-up if there is any birth defect noticed at the birth of child. 


\section{Journal of Exercise Science \& Physiotherapy, Vol. 12, No. 2, 2016 ISSN: 0973-2020 (Print) \\ ISSN: 2454-6089 (Online)}

\section{Conclusion}

It was concluded from the results of the present study that there was a high prevalence rate of $\mathrm{CP}$ and low physical therapy awareness in Panipat city. It was also found that cerebral palsy was significantly influenced by prematurity and low birth weight. Most of the patients who have consulted a physiotherapist, were not taking physical therapy treatment because of long duration of treatment, financial problems and unsatisfactory outcome of the physical therapy treatment. We had motivated parents as well as the society. The results of the present study suggest that we can plan some awareness campaigns about $\mathrm{CP}$ and the role of Physical therapy in its treatment which will help people gain the required information about the disease. Also, time to time camps those offer free diagnosis can help as some of the people face financial problems and do not even get to have a check-up.

\section{Acknowledgement}

The authors wish to thank Mom and Dad you have supported and helped me along the course of this dissertation by giving encouragement and providing the moral and emotional support I needed to complete my thesis. To them, I am eternally grateful.

\section{References}

Bass N.1999. Cerebral palsy and neurodegenerative disease. Curr Opin Pediatr, 11:5047.

Butler C, Campbell S.2000.For the AACPDM Treatment Outcomes Committee Review Panel. Evidence of the effects of intrathecalbaclofen for spastic and dystonic cerebral palsy. Dev Med Children Neurol, 42:634-45.

Hwang, M., Kuroda, M.M., Tann, B., and Gaebler-Spira, D.J.2011. Measuring Care and Comfort in Children with Cerebral Palsy: The Care and Comfort Caregiver Questionnaire. The American Academy of Physical Medicine and Rehabilitation, 3 (10):912-919.

Kyllerman M. Dyskinetic Cerebral Palsy. II.1982.Pathogenetic risk factors and intrauterine growth. Acta Paediatr Scand, 71:551-558.

Maryam OskouiFranzinaCoutinho.2013. "An update on the prevalence of cerebral palsy: a systematic review and meta-analysis" 24th January 2013. Developmental Medicine \& Children Neurology.

Mayer N.H., Esquenazi A., and M.K.1997. Childreners: Common patterns of clinical motor dysfunction. Muscle Nerve Suppl, 20:S21-35.

McLaughlin J., Bjornson K., Temkin N., Steinbok P., Wright V., Reiner A., et al.2002.Selective dorsal rhizotomy: meta-analysis of three randomized controlled trials. Dev Med Children Neurol,44:17-25.

Nadire Berker and SelimYalçin "The Help Guide To Cerebral Palsy Second Edition" classification 2010 By MerillCorporationPage 12- 13.

Vandana J. Rathod, and Jagatheesan Alagesan.2014."Family Awareness Of Legislative Issues On Children With Cerebral Palsy: Cross Sectional Survey",International Journal of Physical Therapy and Research, $\mathrm{Vol}$ 2(3):511-17.

Yudkin P.L. and Johnson A. (1995). "Assessing the contribution of birth asphyxia to cerebral palsy in term singletons",.Journal of Paediatric and Perinatal Epidemiology,9(2):156-70.

Zeljka Petelin Gadze. 2011.Epilepsy in Children - Clinical and Social Aspects. Chapter14, page no 213 Published By InTech.

Conflict of Interest: None Declared 


\title{
A Study of Physical Fitness Profile of Male Gatka Players
}

\author{
Sukhjinder Singh and Ashok Kumar
}

\begin{abstract}
Aim: The aim of the present study was to observe physical fitness profile of male gatka players.Method: Twenty seven $(\mathrm{N}=27)$ healthy trained male gatka players between the ages of 9 and 27 years volunteered for this study. Each participant was performed a vertical jump test, 505 agility test, a maximal right \& left handgrip strength test, queen's step test $\left(\mathrm{VO}_{2} \mathrm{max}\right)$ and flexibility measured at hip with goniometry (right \& left hip flexion).Result: The mean age, height and weight of gatka players was $16.52 \pm 4$.91year, $150.56 \pm 14.40 \mathrm{~cm}$ and $43.00 \pm 12.01 \mathrm{Kg}$. It was found that the scores of vertical jump test, 505 agility test, maximal right \& left handgrip strength test, $\mathrm{VO}_{2} \mathrm{max}$, right \& left hip flexion was $14.66 \pm 4.16 \mathrm{~cm}, 2.91 \pm 0.35$ second, $54.00 \pm 33.66 \mathrm{~kg}, 46.66 \pm 26.85 \mathrm{~kg}$, 54.64 $\pm 5.00 \mathrm{ml} . \mathrm{kg} \cdot \mathrm{min}^{-1}, 121.33 \pm 3.73$ degree and $119.74 \pm 3.35$ degree. Conclusion: It was concluded that the scores of right handgrip strength and right hip flexion were more than the left handgrip strength and left hip flexion and this may be due to the effect of dominant (right) and non-dominant (left) side of gatka players.
\end{abstract}

\section{Sukhjinder Singh}

Student of M.Sc. Sports Science, Department of Sports Science, Punjabi University Patiala (Punjab) India

\section{Ashok Kumar}

Associate Professor, Department of Sports Science,

Punjabi University Patiala (Punjab) India

Email: akashokin@gmail.com

\section{Introduction}

Physical fitness is the ability of the body to function at optimal efficiency. Physical fitness involves skill-related (Speed, Power, Agility, Balance, Reaction time, Coordination) and health-related components (Cardiorespiratory endurance, Muscular strength, Muscular endurance, Flexibility, Body composition). The skill-related components of fitness are important to athletic success and are not crucial for health. The health-related components of fitness are important for health and performance of daily functional activities (Astrand 2000). Gatka is a martial art from the North of India practiced by the Sikhs. Gatka is a style of stick fighting, with wooden sticks intended to simulate swords. By conception, gatka is defensive as well as offensive and focuses on infusing the physical with both the spiritual and mental. The style originated in later 19th century, out of sword practice in the British Indian Army, divided in two sub-style, called rasmi (ritualistic) and khel (sport) from the 1880s. From a physical conditioning perspective, the goal of gatka training is to prepare competitors to effectively manage 
both the physical activity and the physiological demands of combat. In championship, competitors perform long periods of fighting activity interposed with brief periods of non-fighting activity (pause, 30 second). These contests may elicit near maximal heart rate (HR) responses and high lactate concentrations, which infer that high demands may be imposed upon both aerobic and anaerobic metabolism during the bouts. The physical activity and physiological requirements of gatka competition require athletes to be competent in several aspects of fitness, including aerobic and anaerobic power, muscular strength, muscular power, flexibility, speed and agility. It is therefore important that coaches and sports scientists collect objective information about their players' physical performance capabilities to substantiate the objectives of training, establish short and long-term training programmes and provide objective feedback and to motivate athletes during training. Hence the present study was undertaken to observe the different components of physical fitness in trained male gatka players. The alpha level for the data analysis was determined at 0.05 levels.

\section{Results and Discussion}

The mean height and weight of gatka players was $150.56 \pm 14.40 \mathrm{~cm}$ and $43.00 \pm 12.01 \mathrm{Kg}$. Their body mass index (BMI) was 18.48 \pm 2.36 (Table 1).

Table 1. Mean \pm SD of Anthropometric \& Physical Fitness variables of Male Gatka Players

\begin{tabular}{lcc}
\hline Variable(s) & Mean & Std. Deviation \\
\hline Age, year & 16.52 & 4.91 \\
Height, cm & 150.56 & 14.40 \\
Weight, kg & 43.00 & 12.01 \\
BMI, kg/m & 18.48 & 2.36 \\
Leg Power & & \\
Vertical Jump Height, cm & 14.66 & 4.16 \\
Muscular Fitness & & \\
Handgrip Strength Right, kg & 54.00 & 33.66 \\
Handgrip Strength Left, kg & 46.66 & 26.85 \\
Agility & & \\
Agility 505 test (AG505),second & 2.91 & 0.35 \\
Cardiorespiratory Fitness & & \\
VO ${ }_{2}$ max,ml.kg.min & \\
Flexibility (with Goniometry) & 54.64 & 5.00 \\
Hip Flexion (HFR), degree & & \\
Hip Flexion (HFL), degree & 121.33 & 3.73 \\
\hline
\end{tabular}




\section{Journal of Exercise Science \& Physiotherapy, Vol. 12, No. 2, 2016 ISSN: 0973-2020 (Print) \\ ISSN: 2454-6089 (Online)}

The right and left handgrip strength of gatka players was $54.00 \pm 33.66 \mathrm{~kg}$ and $46.66 \pm 26.85 \mathrm{~kg}$. It was found that the absolute and percent difference in the value of right and left handgrip strength was $7.34 \mathrm{~kg}$ and $13.59 \%$ (Table 18). Thus, mean value of right handgrip strength was more than left handgrip strength. This may be due to the effect of dominant (right) and non-dominant (left) hand of the subjects. Further, it was found that the mean difference between right and left handgrip strength was statistical significant $(\mathrm{t}=3.916 \mathrm{p} \leq .01)$ (Table 2).

Table 2. Paired T-test of right and left handgrip strength of gatka players

\begin{tabular}{|c|c|c|c|c|c|}
\hline \multirow{4}{*}{$\begin{array}{l}\text { Right handgrip } \\
\text { strength - Left } \\
\text { hand grip } \\
\text { strength }\end{array}$} & \multirow{3}{*}{$\begin{array}{c}\text { Mean } \\
\text { Difference }\end{array}$} & \multicolumn{2}{|c|}{ Paired Differences } & \multirow{3}{*}{\multicolumn{2}{|c|}{$\begin{array}{c}\text { Sig. } \\
(2- \\
\text { tailed }\end{array}$}} \\
\hline & & \multicolumn{2}{|c|}{$\begin{array}{l}\text { 95\% Confidence Interval of the } \\
\text { Difference }\end{array}$} & & \\
\hline & & Lower & Upper & & \\
\hline & 7.33333 & 3.48388 & 11.18279 & 3.916 & .001 \\
\hline
\end{tabular}

The vertical jump height of gatka players was $14.66 \pm 4.16 \mathrm{~cm}$ (Table 1). A heavier person jumping the same height as a lighter person has to do more work as they have a larger mass to move. It is sometimes useful to convert the vertical jump height to units of power. Power cannot be calculated (Power $=$ Work $\div$ Time) since the Time the force is acted on the body is unknown. Formulas have been developed that estimate power from vertical jump measurements. In these formulas mass $=$ body weight and $\mathrm{VJ}=$ Vertical Jump height.

Johnson and Bahamonde (1996) established equations for peak and average power.

- $\quad$ Peak power $(\mathrm{W})=78.5 \times \mathrm{VJ}(\mathrm{cm})+60.6 \times$ mass $(\mathrm{kg})-15.3 \times$ height $(\mathrm{cm})-$ 1308

- $\quad$ Average power $(\mathrm{W})=41.4 \times \mathrm{VJ}(\mathrm{cm})+31.2 \times$ mass $(\mathrm{kg})-13.9 \times$ height $(\mathrm{cm})+431$

Thus, in the present study an estimated average power was 49 watts and peak power was 134 watts of gatka players.

The agility test (505 agility test) score of gatka players was $2.91 \pm 0.35$ second. On the basis of the time taken for 505 agility test, an estimated subject's speed was 11.24 feet $/ \mathrm{sec}$ or $7.67 \mathrm{mphbor} 3.43 \mathrm{~m} / \mathrm{sec}$ or $12.34 \mathrm{~km} / \mathrm{hr}$.

An estimated $\mathrm{VO}_{2} \max$ (Queen's college step test) of gatka players was $54.64 \pm 5.00$ ml.kg. $\min ^{-1}$

The right and left hip flexion of gatka players was $121.33 \pm 3.73^{\circ}$ and $119.74 \pm 3.35^{\circ}$ and was in the normal range (Table1). The mean value of right hip flexion was more than left hip flexion. Further, it was found that the mean difference between right and left hip flexion was statistical significant $(t=5.937 \mathrm{p} \leq .01)$ (Table 3$)$. 
Journal of Exercise Science \& Physiotherapy, Vol. 12, No. 2, 2016

ISSN: 0973-2020 (Print)

ISSN: 2454-6089 (Online)

Table 3. Paired T-test of Right and Left Hip Flexion of Gatka Players

\begin{tabular}{|c|c|c|c|c|c|}
\hline \multirow{3}{*}{$\begin{array}{l}\text { Right hip } \\
\text { flexion-Left } \\
\text { hip flexion }\end{array}$} & \multirow{3}{*}{$\begin{array}{c}\text { Mean } \\
\text { Difference }\end{array}$} & \multicolumn{2}{|c|}{ Paired Differences } & \multirow[b]{3}{*}{ t } & \multirow{3}{*}{$\begin{array}{l}\text { Sig. } \\
(2- \\
\text { tailed) }\end{array}$} \\
\hline & & \multicolumn{2}{|c|}{$\begin{array}{l}\text { 95\% Confidence Interval of the } \\
\text { Difference }\end{array}$} & & \\
\hline & & Lower & Upper & & \\
\hline & 1.59259 & 1.04118 & 2.14401 & 5.937 & .000 \\
\hline
\end{tabular}

\section{Conclusion}

It was concluded that the scores of right handgrip strength and right hip flexion were more than the left handgrip strength and left hip flexion and this may be due to the effect of dominant (right) and non-dominant (left) side of gatka players.

\section{Acknowledgment}

The authors thank all the subjects who voluntarily participated in this study.

\section{References}

Astrand, P.O.2000. Endurance Sports. In Endurance in Sport: Volume II of the Encyclopedia of Sports Medicine an IOC Medical Commission Publication In Collaboration with the International Federation of Sports Medicine. Eds R.J. Shephard and P.-O. Astrand, Second Edition, Blackwell Science. pp 9-15. ISBN 0-632-05348-8.

Johnson, Doug L and Bahamonde, Rafael.1996. Power Output Estimate in University Athletes. Journal of Strength \& Conditioning Research, 10 (3),161-166.

Conflict of Interest: None Declared 


\title{
A Comparative Study of Dietary Intake and Expenditure of Urban and Rural Adolescent Girls age 15-16 years
}

\author{
Narinder Kaur, Ashok Kumar and Vishal Kumar
}

\begin{abstract}
Aim: A comparative study of dietary intake and expenditure of urban and rural adolescent girls age 15-16 years. Material \& Methods: The study was conducted on 60 urban (age 16.09 \pm 0.62 years) and 60 rural (age 15.86 \pm 0.60 years) adolescent girls. All subjects were taken from district Sangrur (Punjab). DINE healthy software, version (1994-1997 dine healthy system was used for the dietary analysis of food consumed by the subjects. Through this software nutrient intake and energy expenditure was calculated. Three days recall method was used to determine caloric intake and all activities with duration done by subjects for 24 hour were recorded for energy expenditure. Results: Dietary intake of urban and rural girls was $2324.28 \pm 192.11 \mathrm{kcal}$ and $2366.93 \pm 221.69 \mathrm{kcal}$ respectively. Energy expenditure of urban girls was $2451.63 \pm 165.93 \mathrm{kcal}$ and rural girls were $2599.37 \pm 144.95 \mathrm{kcal}$. Conclusion: The results showed that the urban and rural girls were taking sufficient dietary intake. But urban girls' energy expenditure was below than the rural girls. Both urban and rural adolescent girls were taking extra energy from fat that was 46 per cent and 46.77 per cent respectively.
\end{abstract}

Narinder Kaur

Ph.D. Research Scholar, Department of Sports

Science, Punjabi University Patiala (Punjab)

India

Ashok Kumar

Associate Professor, Department of Sports

Science, Punjabi University Patiala (Punjab)

India

Email: akashokin@gmail.com

\section{Vishal Kumar}

Ph.D. Research Scholar, Department of Sports

Science, Punjabi University Patiala (Punjab)

India

E-mail:vishalkandiara@yahoo.com

\section{Introduction}

World Health Organization defines adolescence as the segment of life between the ages of 10-19 years. Adolescence is a transitional stage of life development through which a child becomes an adult. At this stage the bodies of an adolescent girl are not like a child anymore but are also not quite yet adult bodies. Balanced nutrition is utmost important in these young adult's life. For females required a diet consist of food, vegetables, whole grains, lean meats and low-fat dairy for strong bones and prevention of osteoporosis later in life calcium is required. India is in state of nutritional transition, where urbanization has contributed to shift in diet and obesity is on rise with micronutrients deficiency and protein energy malnutrition continues to be present. Under nutrition among early 


\section{Journal of Exercise Science \& Physiotherapy, Vol. 12, No. 2, 2016 ISSN: 0973-2020 (Print) \\ ISSN: 2454-6089 (Online)}

adolescent girls of rural areas in India is a major health problem (Maiti et al., 2011).Adolescents need additional nourishing diet as the foundation for lifetime in health; strength and intellectual validity is laid during this period of age (Kapil et al., 1993). Dietary intake is a product of many variables like family income and family size, socio-economic status, mother's occupational, father's occupation and knowledge of sound nutritional practices which would ultimately affect the physical growth (Tamilsari and Sasirekha 1990, Cole et al., 1997). Adolescents are unaware of the foods essential for good health, eat very few of the food which supply the basic nutrients (Thomas and Call 1973). Meal skipping greater use of fast foods and fad diets contribute to poor dietary intake among young people (Jakobivitis et al., 1977). Most of the children eat improperly. Only 83.2 per cent have their breakfast regular and 62.6 per cent have regular light lunch. Rural children have consumed 34.9 per cent sweets but fruits and vegetables in low quantity. Eating habits may depend on parent's education and household situations (Kollataj et al., 2011).

\section{Material \& Methods}

An attempt has been made to study the Dietary analysis of 120 urban and rural adolescent girls. The subjects were divided into urban and rural groups on the basis of their residence. Each group was comprised of 60 girls. All the subjects were ranging in age 1516 years. Various parameters measured in the present study on urban and rural girls have been enlisted follow:

I. General Physical Characteristics

I. Dietary Intake and Energy Expenditure
1. Age (years)

2. Height (cms)

3. Weight (kgs)

4. BMI $\left(\mathrm{kg} / \mathrm{m}^{2}\right)$

- Nutrient intake-Major nutrients:

- Daily dietary intake of carbohydrates

- Daily dietary intake of fats

- Daily dietary intake of proteins

- Energy Intake (EI)

- Energy Expenditure (EE)

To determining the caloric intake, a three days recall method was used that is during three days everything eaten and drunk along with the specific amount eaten by the subject was recorded. All activities of the subject completed in 24 hours was recorded with duration of activity and category of activity. DINE healthy software, version (O1994-1997 dine system was used for the dietary analysis of food consumed by the subject. With the help of this software nutrient intake and energy expenditure of the subjects was calculated. 
Journal of Exercise Science \& Physiotherapy, Vol. 12, No. 2, 2016

ISSN: 0973-2020 (Print)

ISSN: 2454-6089 (Online)

Results and Discussions

Table 1. Mean SD of Dietary Intake \& Expenditure of Urban Adolescent Girls

\begin{tabular}{|c|c|c|c|}
\hline Variables & Mean & S.D. & $\begin{array}{l}\text { dietary } \\
\text { intake \% }\end{array}$ \\
\hline Age (years) & 16.09 & 0.62 & \\
\hline Height (cms) & 153.1 & 6.71 & \\
\hline Weight (kgs) & 44.47 & 8.12 & \\
\hline BMI $\left(\mathrm{kg} / \mathbf{m}^{2}\right)$ & 18.97 & 2.93 & \\
\hline $\begin{array}{l}\text { Daily dietary intake of } \\
\text { carbohydrates (gm) }\end{array}$ & $\begin{array}{l}\mathbf{1 0 6 3 . 0 9} \\
\text { (Calorie) } \\
266(\mathrm{gm})\end{array}$ & 33.35 & 45.83 \\
\hline Daily dietary intake of fats (gm) & $\begin{array}{l}1071.46 \\
\text { (Calorie) } \\
\text { 118.83 (gm) }\end{array}$ & 17.84 & 46 \\
\hline Daily dietary intake of proteins (gm) & $\begin{array}{l}244.47 \text { (Calorie) } \\
60.96(\mathrm{gm})\end{array}$ & 10.10 & 10.10 \\
\hline Energy Intake (EI) (Kcal) & 2324.38 & 192.11 & \\
\hline Energy Expenditure (EE) (Kcal) & 2451.63 & 165.93 & \\
\hline
\end{tabular}

The mean age, height, weight and BMI of urban adolescent girls were $16.09 \pm 0.62$ year, $153.1 \pm 6.71 \mathrm{~cm}, 44.47 \pm 8.12 \mathrm{~kg}$ and $18.97 \pm 2.93 \mathrm{~kg} / \mathrm{m}^{2}$ respectively (Table 1 ). The daily dietary intake of carbohydrates, fats and proteins of urban adolescent girls were $266 \pm 33.35 \mathrm{gm}, 118.83 \pm 17.84 \mathrm{gm}, 60.96 \pm 10.10 \mathrm{gm}$ respectively. The energy intake of urban adolescent Punjabi girls was 2324.38 $\pm 192.11 \mathrm{kcal}$ and energy expenditure was $2451.63 \pm 165.93 \mathrm{kcal}$ (Table 1).

Table 2. Mean SD of Dietary Intake \& Expenditure of Rural Adolescent Girls

\begin{tabular}{|c|c|c|c|}
\hline Variables & Mean & S.D. & $\begin{array}{l}\text { dietary } \\
\text { intake \% }\end{array}$ \\
\hline Age (years) & 15.86 & $\mathbf{0 . 6 0}$ & \\
\hline Height (cms) & 155.2 & 7.14 & \\
\hline Weight (kgs) & 44.25 & 6.51 & \\
\hline BMI $\left(\mathbf{k g} / \mathbf{m}^{2}\right)$ & 18.39 & 2.62 & \\
\hline $\begin{array}{l}\text { Daily dietary intake of } \\
\text { carbohydrates (gm) }\end{array}$ & $\begin{array}{l}\text { 1063.48(Calorie) } \\
266.17 \text { (gm) }\end{array}$ & 37.48 & 45.15 \\
\hline Daily dietary intake of fats (gm) & $\begin{array}{l}\text { 1112.72(Calorie) } \\
123.47(\mathrm{gm})\end{array}$ & 23.59 & 46.77 \\
\hline $\begin{array}{l}\text { Daily dietary intake of proteins } \\
\text { (gm) }\end{array}$ & $\begin{array}{l}246.21 \text { (Calorie) } \\
62.26(\mathrm{gm})\end{array}$ & 12.80 & 10.41 \\
\hline Energy Intake (EI) (Kcal) & 2366.93 & 221.69 & \\
\hline Energy Expenditure (EE) (Kcal) & 2599.37 & 144.95 & \\
\hline
\end{tabular}

The mean age, height, weight and BMI of rural adolescent girls were 15.86 \pm 0.60 year, $155.2 \pm 7.14 \mathrm{~cm}, 44.25 \pm 6.51 \mathrm{~kg}$ and $18.39 \pm 2.62 \mathrm{~kg} / \mathrm{m}^{2}$ respectively (Table 1 ). The daily 


\section{Journal of Exercise Science \& Physiotherapy, Vol. 12, No. 2, 2016 \\ ISSN: 0973-2020 (Print) \\ ISSN: 2454-6089 (Online)}

dietary intake of carbohydrates, fats and proteins of rural adolescent girls were 266.17 $\pm 37.48 \mathrm{gm}, 123.47 \pm 17.823 .594 \mathrm{gm}, 62.26 \pm 12.80 \mathrm{gm}$ respectively. The energy intake of rural adolescent Punjabi girls was $2366.93 \pm 221.69 \mathrm{kcal}$ and energy expenditure was $2599.37 \pm 144.95 \mathrm{kcal}$ (Table 2).

\section{Discussion}

Furthermore, both groups of adolescent girls also put on display statistically insignificant difference in percent contribution of carbohydrates, fats and protein and in total energy intake. Rural girls displayed more energy expenditure than urban girls. It has been explored from the above-mentioned review of literature that most of the countries of the world are experiencing deterioration in nutritional of their young generation. Therefore, the results of the present study will also be helpful in providing the information regarding nutritional status of rural and urban Punjabi adolescent girls.

\section{Acknowledgment}

Thank to all the subjects who were voluntarily participated in this study.

\section{Conclusion}

The results showed that the urban and rural girls were taking sufficient dietary intake. But urban girls' energy expenditure was below than the rural girls. Both urban and rural adolescent girls were taking extra energy from fat that was 46 per cent and 46.77 per cent respectively.

\section{References}

Cole, A.H., Taiwoo, O., Nuragbara, and Cole, C.E. (1997) Energy intake, anthropometry and composition of Nigerian adolescent girls: A case study of an institutionalized secondary school in Ibadan. Br.J. Nutr.77:495-509.

Dine system, Inc. (1997) National Institute of Health, Public Health Service and Department of Health and Human Services Nee York, USA.

Jakobivits, C.; Halstead, P.; Kelley,L.; Roe, D.A. and Young, C.M. (1977) Eating habits and nutrient intake of college women over a thirty year period. Am.J. Dietet.Association.71:405-411.

Kapil, U.; Manocha, S. and Bhasin, S. (1993) Dietary intake amongst well to do adolescent boys and girls in Delhi. Paediat,30:1017-1021.

Kołłątaj W, Sygit K, Sygit M, Karwat ID, Kołłątaj B. (2011) Eating habits of children and adolescents from rural regions depending on gender, education, and economic status of parents. Ann Agric Environ Med.18(2):393-7.

Maiti S, KM Ali,D De, TK Bera, D Ghosh, S Paul (2011)A Comparative Study on Nutritional Status of Urban and Rural Early Adolescent School Girls of West Bengal, India. Journal of Nepal Paediatric Society, Vol 31, No 3.

Tamilsari,P. and Sasirekha, N.S. (1990) Body weight, diet, serum cholesterol level in selected obese girls. Ind.J.Nutr.Dietet.27:35-38.

Thomas, J.A. and call, D.L. (1973) Eating between meals- A nutritional probem among teenagers. Nutr.Rev.31:137-139.

\section{Conflict of Interest: None Declared}




\title{
Comparison of Auditory Response Time in Physically Active and Non- Active Type 2 Diabetics
}

\author{
Vishal Kumar, Ashok Kumar and Narinder Kaur
}

\begin{abstract}
Aim: To study the auditory response time of physically active type 2 diabetics and nonactive type 2 diabetics. Materials \& Method: The study was conducted on 30 physically active type 2 diabetics (age 46 \pm 3 years) and 30 physically non-active type 2 diabetics (46 \pm 3 years) males. Response Analyzer (audio-visual response time instrument) was used to measure the auditory response time. The stimulus was given by the buzzer and subject was required to response to the stimulus by pressing an appropriate button. Result: Audio 1 ( $1.08 \pm 0.46 \mathrm{~ms})$, Audio 2 (1.05 $\pm 0.42 \mathrm{~ms})$, Audio3 (1.08 \pm 0.40$) \mathrm{ms}$, Audio $4(1.11 \pm 0.39$ $\mathrm{ms})$ and combined auditory response time $(1.08 \pm 0.33 \mathrm{~ms})$ of physically active type 2 diabetics and Audio 1, Audio 2, Audio3, Audio 4 and combined auditory response time of physically non-active type 2 diabetics was $1.02 \pm 0.31 \mathrm{~ms}, 1.11 \pm 0.44 \mathrm{~ms}, 1.18 \pm 0.58$ $\mathrm{ms}, 1.27 \pm 0.52 \mathrm{~ms}, 1.14 \pm 0.37 \mathrm{~ms}$ respectively. Conclusion: It was concluded that the auditory response time was delayed in non-active type 2 diabetics than physically- active type 2 diabetics.
\end{abstract}

\section{Vishal Kumar}

Ph.D. Research Scholar, Department of Sports

Science, Punjabi University Patiala (Punjab) India

E-mail:vishalkandiara@yahoo.com

\section{Ashok Kumar}

Associate Professor, Department of Sports Science,

Punjabi University Patiala (Punjab) India

Email: akashokin@gmail.com

Narinder Kaur

Ph.D. Research Scholar, Department of Sports

Science, Punjabi University Patiala (Punjab) India
Key Words: Diabetes Mellitus, Audio, Visual

DOI: $10.18376 / j e s p / 2016 / v 12 / \mathrm{i} 2 / 111266$

\section{Introduction}

Physical inactivity and Obesity independently contribute to the development of type 2 diabetes; however, the magnitude of risk contributed by obesity is much greater than that imparted by lack of physical activity. It knows that physical training has positive effects on reaction time (Davranche et al., 2006 and Little and Williams 2005). Physical activity contributes to several positive effects on both physicaland mental health (Blair et al., 2001; Hallal et al., 2006). Obesity and physical inactivity are well-known risk factors for the development of type 2 diabetes (Chan JM et al., $1994-\mathrm{Hu}$ FB et al., 1999). A 


\section{Journal of Exercise Science \& Physiotherapy, Vol. 12, No. 2, 2016 ISSN: 0973-2020 (Print) \\ ISSN: 2454-6089 (Online)}

reaction time measurement is a reliable indicator of processing of sensory stimulus by central nervous system and its execution in the form of a motor response (Aley $L$ et al., 2007). It is an important method used for central information processing, speed and coordinate peripheral movement responses (Batra A et al., 2014). Type 2 diabetes is a major cause of morbidity and mortality and has become an important public health issue worldwide (Perkins2004). The relative risk of death is approximately 20\% to 35\% lower in physically active and fit persons compared to that in inactive and unfit persons(Warburton et al., 2006, Samitz et al., 2011).Physically exercise has been considered a cornerstone of diabetes management, along with diet and medication. However, high-quality evidence on the importance of exercise and fitness in diabetes was lacking until recent years.(Sigal et al., 2004).

\section{Materials and Methods}

Subjects- All the subjects were participated in the study voluntarily. There were 60 type 2 diabetics male subjects and out of which 30 were physically active and 30 non- active type 2 diabetics and their age ranged from 40-50 years. All the subjects were right handed, non-smokers, non-alcoholic. The auditory response time was measured by digital response time instrument, which is specially designed to measure response time in seconds that was Response Analyzer which had a display accuracy of 0.001 second. The auditory response time was recorded for low, medium, high and very high frequency sound stimuli. The stimulus was given by the buzzer. The subject was required to response to the stimulus by pressing an appropriate button. As soon as the stimuli was perceived by the subject, he responded by pressing an appropriate response switch. The display screen of the instrument indicated the response time in seconds. All subjects were given practice trails and were instructed to react as quickly as possible on every trial. The average of the three readings was taken as the value for auditory response time.

Data were analyzed using the Statistical Package for Social Sciences Software (SPSS 16.0 free trial version for Windows, SPSS Inc., Chicago, IL, USA). Mean and standard deviation was calculated.

\section{Results and Discussion}

Table 1. Descriptive Statistics of Physically-active Type 2 diabetics

\begin{tabular}{lll}
\hline Variables & Mean & $\begin{array}{l}\text { Standard } \\
\text { deviation }\end{array}$ \\
\hline Age(years) & 46.03 & 3.16 \\
Height (cms) & 171.97 & 7.70 \\
Weight(kg) & 78.46 & 11.75 \\
Body Mass Index (kg/m ${ }^{2}$ ) & 26.47 & 3.69 \\
Audio-1 (very high frequency sound) (sec) & 1.08 & 0.46 \\
Audio-2 (high frequency sound) (sec) & 1.05 & 0.42 \\
Audio-3 (medium frequency sound) (sec) & 1.08 & 0.40 \\
Audio-4 (low frequency sound) (sec) & 1.11 & 0.39 \\
Combined audio (1+2+3+4) (sec) & 1.08 & 0.33 \\
\hline
\end{tabular}


Journal of Exercise Science \& Physiotherapy, Vol. 12, No. 2, 2016

ISSN: 0973-2020 (Print)

ISSN: 2454-6089 (Online)

Table 2. Descriptive Statistics of physically non-active type 2 diabetics

\begin{tabular}{lll}
\hline Variables & Mean & $\begin{array}{l}\text { Standard } \\
\text { deviation }\end{array}$ \\
\hline Age(years) & 46.70 & 3.77 \\
Height (cms) & 170.30 & 5.74 \\
Weight(kg) & 78.77 & 17.34 \\
Body Mass Index (kg/m ${ }^{2}$ ) & 27.10 & 5.52 \\
Audio-1 (very high frequency sound) (sec) & 1.02 & 0.31 \\
Audio-2 (high frequency sound) (sec) & 1.11 & 0.44 \\
Audio-3 (medium frequency sound) (sec) & 1.18 & 0.58 \\
Audio-4 (low frequency sound) (sec) & 1.27 & 0.52 \\
Combined audio (1+2+3+4) (sec) & 1.14 & 0.37 \\
\hline
\end{tabular}

\section{Discussion}

Table 1 and Table 2 shows mean height, weight, body mass index, auditory response time of physically active and non-active of type 2 diabetics. It was observed from results is that auditory response time was less that is better in physically active type 2 diabetics than non-active type 2 diabetics.

\section{Conclusion}

It was concluded that the auditory response time was delayed in non-active type 2 diabetics than physically- active type 2 diabetics.

\section{Acknowledgment}

Thank to all the subjects who voluntarily participated in this study.

\section{Reference}

Aley L, Miller EW, Bode S, Hall L, Markusic J,Nicholson M et al..2007. Effects of age, task complexity and exercise on reaction time of women during ambulation tasks. J Geriatr Phys Ther 30(1):3-7.

Batra A, Vyas S, Gupta J, Gupta K, Hada R.2014. Acomparative study between young and elderly Indian males on audio-visual reaction time. Indian Journal of Scientific Research and Technology 2(1): 25-29. 
Blair SN, Cheng Y, Holder J S.2001. Is physical activity or physical fitness more important in defining health benefits? Med Sci Sports Exerc 33(6 Suppl) S379-399 discussion S419-320

Chan JM, Rimm EB, Colditz GA, Stampfer MJ, Willett WC.1994.Obesity, fat distribution, and weight gain as risk factors for clinical diabetes in men. Diabetes Care 17:961-969.

Warburton D. E. R., C. W. Nicol, and S. S. D. Bredin.2006.Health benefits of physical activity: the evidence," CMAJ, vol. 174, no. 6, pp. 801-809.

Davranche, K., M. Audiffren, and A. Denjean. 2006. A distributional analysis of the effect of physical exercise on a choice reaction time task. Journal of Sports Sciences 24(3): 323-330.

Samitz G., M. Egger, and M. Zwahlen.2011.Domains of physical activity and allcause mortality: systematic review and dose-response meta-analysis of cohort studies. International Journal of Epidemiology, vol. 40, no. 5, Article ID dyr112, pp. 1382-1400.

Hallal PC, Victora CG, Azevedo MR, Wells JC .2006.Adolescent physical activity and health: a systematic review. Sports Med 36 (12) 1019-1030.

Hu FB, Sigal RJ, Rich-Edwards JW, Colditz GA, Solomon CG, Willett WC, Speizer FE, Manson JE.1999. Walking compared with vigorous physical activity and risk of type 2 diabetes in women: a prospective study. JAMA282:1433-1439.

Little T, Williams AG.2005. Specificity of acceleration, maximum speed, and agility in professional soccer players. J Strengh Cond Res 19:76-8.

Perkins I.2004.Diabetes mellitus epidemiology-classification, determinants, and public health impacts. J Miss State Med Assoc 45: 355-362.

Sigal RJ, Kenny GP, Wasserman DH, Castaneda-Sceppa C.2004. Physical activity/exercise and type 2 diabetes. Diabetes Care 27: 2518-2539.

Conflict of Interest: None Declared 


\section{Journal of Exercise Science \& Physiotherapy, Vol. 12, No. 2, 2016 \\ ISSN: 0973-2020 (Print) \\ ISSN: 2454-6089 (Online)}

\section{Instructions to Contributors}

Journal of Exercise Science and Physiotherapy (JESP) is the official journal of the Exercise Fitness and Health Alliance (www.efha.in). Journal of Exercise Science and Physiotherapy (JESP) is a scientific peer reviewed journal, publishing research studies and review articles in the field of sports injuries, physiotherapy, exercise physiology, sports rehabilitation, sports medicine, diseases and exercise, sports psychology, nutrition, physical education, sports biomechanics, kinesiology, molecular exercise science, health fitness \& technology and sports education.

JESP is published biannually in the month of June and December but is planned to be published quarterly in the near future. Articles written in English should be sent to the editor-in-chief or assistant editor of JESP. The research paper for publication in the journal should be sent only in typed manuscript form as email directly to satishsk1@rediffmail.com or akashokin@gmail.com

\section{Mission}

JESP aims to present easy access to the scientific knowledge for health \& sport conscious individuals. The purpose is to minimise the problems like the delays in publishing process of the articles by drawing advantage from electronic medium.

\section{Instructions to Authors}

The articles may be submitted to the Editor-in-chief or Assistant Editor, JESP (email: satishsk1@ rediffmail.com OR akashokin@gmail.com). Manuscripts are considered if they are submitted only to JESP and therefore should not be under consideration for publication elsewhere, either in part or in whole. Authors are responsible for the scientific context and legal aspects of the articles. Editors may make necessary changes to articles in accordance with "Instructions to Authors". Normally the complete research paper should not exceed 15 typed pages including tables and figures; however under exceptional circumstances this limit can be relaxed. There is no page and reference limitation for the review articles. All files related to manuscripts should be submitted electronically. Text files should be in Microsoft Word versions. Each figure, table, photograph or other image should be submitted electronically. The manuscripts should be submitted in Times New Roman font, 12-point type, double-spaced with $3 \mathrm{~cm}$ margins on all sides. The reference style used by the Journal is the Harvard System of referencing.

\section{Format for Research Article}

Include the following sections in research articles without page space:

Title: Capital letters.

Authors: Surname followed by initials and institution(s) where the study was conducted. 


\section{Journal of Exercise Science \& Physiotherapy, Vol. 12, No. 2, 2016}

ISSN: 0973-2020 (Print)

ISSN: 2454-6089 (Online)

Abstract: an abstract of not more than 150 words that includes objectives, methods, results and conclusions.

KEY WORDS: To assist in indexing the journal, list up to 6 key words (not from title), which your article could be indexed.

\section{INTRODUCTION}

\section{METHODS}

RESULTS

DISCUSSION

CONCLUSION

ACKNOWLEDGMENTS: Provide information sufficient to identify sources of support, technical assistance, and intellectual contributions not associated with authorship.

REFERENCES: Each citation in the text must be noted by surname and year in parentheses and must appear in the reference section as an alphabetic order. Example for citation in the text; a) for single author (Gür, 1999), b) for two authors (Gür and Akova, 2001), c) more than two authors (Gür et al., 2000).

\section{Journal Article:}

Akova, B., Sürmen-Gür, E., Gür, H., Dirican, M., Sarandöl, E. and Kücükoglu, S. 2001. Exercise-induced oxidative stress and muscular performance in healthy women: role of vitamin E supplementation and endogenous estradiol. European Journal of Applied Physiology, 84: 141-147.

Journal Article, Article not in English:

Seker-Aygül, Z., Akova, B. and Gür, H. 2001. The relationship of stress and stress management factors with injury in soccer players. Turkish Journal of Sports Medicine, 36: 71-80. (In Turkish: English abstract).

\section{Journal Article in press:}

Gür, H., Cakin, N., Akova, B., Okay, E. and Kücükoglu, S 2002. Concentric versus combined concentric- eccentric isokinetic training: Effects on functional capacity and symptoms in patients with osteoarthrosis of the knee. Archives of Physical Medicine and Rehabilitation, in press. 


\section{Journal Article in electronic format:}

Weigand, D.A., Carr, S., Petherick, C. and Taylor, A. 2001. Motivational climate in Sport and Physical Education: The role of significant others. European Journal of Sports Science (serial online) 1(4), (13 screens/inclusive page), October. Available from URL: http://www.humankinetics.com/ejss

Book:

Guyton, A.C. and Hall, J.E. 1996. Textbook of medical physiology. 9th edition. W. B. Saunders Company, London.

Chapter in edited book:

Wilson, C.H. 1984. Exercise for arthritis. In: Therapeutic exercise. Ed: Basmajian, J.V. $4^{\text {th }}$ edition. Baltimore: Williams and Wilkins. 529-545.

Thesis:

Özyener, F. 2000. Effects of work intensity on dynamics of pulmonary gas exchange during exercise in humans. Doctoral thesis, University of London, London. 79.

\section{Thesis not in English:}

Özer, Ö. 2001. The effect of muscle exercise to oxygen kinetics in chronic smokers. Doctoral thesis, University of Uludag, Bursa. 1-54. (In Turkish: English abstract).

\section{LEGENDS}

AUTHOR BIOGRAPHY: Please include a brief biography, approximately 50 words per author, for each author including (1) academic title/degrees, (2) institution affiliation, (3) research focus, (4) post and e-mail addresses.

TABLES, FIGURES, etc.: The location within the article where e.g. figures and tables appear should be indicated in the text. These materials (e.g. table, figure) should be submitted separately from the text document. Each item should be produced in Microsoft Office (Word, Excel, or PowerPoint), GIF or JPEG format. Submit each item separately and number sequentially as (main author) Figure 1.jpg, (main author) Figure2.jpg, and so on, for example, GurFigure1.jpg and GurTable1.doc.

\section{FORMAT FOR REVIEW ARTICLE}

Include the following sections in research articles without page space:

TITLE: Capital letters.

AUTHORS: Surname followed by initials and institution(s) where the study was conducted.

ABSTRACT: Include an abstract of not more than 300 words.

KEY WORDS: To assist in indexing the journal, list up to 6 key words (not from title), which your article could be indexed

\section{MAIN TEXT}

\section{CONCLUSION}

\section{ACKNOWLEDGMENT}

REFERENCES: Each citation in the text must be noted by surname and year in parentheses and must appear in the reference section as an alphabetic order. Example for 


\section{Journal of Exercise Science \& Physiotherapy, Vol. 12, No. 2, 2016 \\ ISSN: 0973-2020 (Print) \\ ISSN: 2454-6089 (Online)}

citation in the text; a) for single author (Gür, 1999), b) for two authors (Gür and Akova, 2001), c) more than two authors (Gür et al., 2000). See the reference section of research article for detail.

\section{LEGENDS}

AUTHOR BIOGRAPHY: For detail see the author biography section of research article.

TABLES, FIGURES, etc.: For details see the tables, figures, section of research article.

\section{REVIEW AND PUBLISHING POLICY}

Upon receipt of a manuscript the editor will notify the main author that the submission has been received. The manuscript will undergo a blinded review process. Under this process the editor will forward (electronically) the manuscript to two independent reviewers. Normally the review process will take approximately 4 weeks. After the review process has been completed the main author will be notified via E-mail either of acceptance, revision or rejection of the manuscript. If the main author has not been informed of the results of the review process after 8 weeks from the date of confirmation of receipt of the manuscript (by the editor), the author should notify the editor-in-chief directly. If revision was recommended, this should be completed and returned to the editor within 4 weeks; failure to return the revised manuscript within the allotted time span will lead to rejection of the manuscript. When a manuscript has been accepted for publication it will be forwarded to the editor-in-chief for final approval. The editor-inchief will work with the main author to make necessary revisions in order for the manuscript to appear in the Journal of Exercise Science and Physiotherapy. The final proof of the manuscript will be sent to the main author as an E-mail attachment. If the main author requires any minor changes to the finished work, these should be submitted electronically to the editor-in-chief within one week. Manuscript accepted in the first half of the year will be published not later than the second half of the year.

\section{Checklist for Authors}

- Double-space manuscript text and use $3 \mathrm{~cm}$ margins on all sides, and Times New Roman, 12-point type, English and SI units.

- Include with text a title, abstract, key words, figure and table lists, figure and table legends.

- Submit all materials electronically-Email.

- Include complete author names, addresses, e-mail, phone and fax numbers.

- Include a short ( $\sim 50$ words) author biography for each author. 


\section{Journal of Exercise Science \& Physiotherapy, Vol. 12, No. 2, 2016 \\ ISSN: 0973-2020 (Print) \\ ISSN: 2454-6089 (Online)}

\section{PROCESSING FEE}

As costs are involved in every stage of the publication process, like manuscript handling form submission to publication, peer-review, copy-editing, typesetting, tagging and indexing of articles, Electronic composition and production, hosting the final article on dedicated servers, electronic archiving, server and website update and maintenance, supporting sales and marketing costs to ensure global dissemination and administrative and overheads, the author is asked to pay an article publication fee.

- A publication fee of Rs.3000/- per article up to 8000 word including title, text, tables, figures, spaces and thereafter for each extra page Rs.500/- per page should be charged for the printed paper in the journal for Indian Authors.

- A publication fee of US\$ 50 per article up to 8000 word including title, text, tables, figures, spaces and thereafter for each extra page US\$ 10 per page should be charged for the printed paper in the journal for Foreign Authors.

Authors can remit their processing fee through Internet Banking or by Demand Draft for which the details are given below. We request you to make the payment within seven days after receiving acceptance or your paper status stands "Waiting for payment". After making payment, Send an email to satishsk1@rediffmail.com or akashokin@gmail.com email should contain the following details,

Scanned copy of Bank transaction slip or Bank deposit slip (Chelan Copy)

Scanned copy of copyright form should be duly filled and signed by corresponding author (mandatory) and Co-author's.

Always mention your manuscript ID (if assigned) and tile of the paper in all communication.

Note: Without signed copy of copyright form the paper will not be selected for publication and will not be published.

Please take care of making the payment before due date to avoid delaying the process.

\section{Details of Processing fee for Indian Authors}

Processing fee of Rs.3000/- Indian Rupees or US\$ 50per article up to 8000 words charged for manuscripts those are found eligible for Publication for Authors from India or Foreign country. The author will be informed about the number pages the accepted paper will occupy. 
Online Fund Transfer Details

\begin{tabular}{|l|l|}
\hline Bank Name: & ORIENTAL BANK OF COMMERCE \\
\hline Address of the Bank Branch: & $\begin{array}{l}\text { Gurbax Colony, Patiala -147001 (Punjab) } \\
\text { India }\end{array}$ \\
\hline Name of the Account Holder: & $\begin{array}{l}\text { EXERCISE FITNESS \& HEALTH } \\
\text { ALLIANCE }\end{array}$ \\
\hline Account Number: & $\mathbf{0 7 3 9 2 0 1 1 0 1 4 4 1 5}$ \\
\hline IFSC Code: & ORCO100739 \\
\hline MICR Code: & 147022009 \\
\hline
\end{tabular}

Note: 1.EFHA prefers Online Fund transfers

2. There is No Bank Account under name of Journal of Exercise Science \& Physiotherapy

3. Please attach a scan copy of online fund transfer receipt from your bank

4. If the author pays by Bank Demand Draft. Please write subscriber's name, Address, mobile no. and email ID on the back side of Bank Demand Draft

Editor-in-Chief

JESP 